\title{
OS DISTURBIOS DO CRESCIMENTO E AS GLANDULAS DE SECREÇÃO INTERNA
}

\author{
DR. PAULO DE ALMEIDA TOLEDO
}

Livre-docente e assistente extranumerario da Faculdade de Medicina da Universidade de S. Paulo.

\section{SUMARIO}

$1 .^{\circ}$ - Considerações gerais. As glandulas de secreção interna e seu papel no desenvolvimento corporal. $\mathrm{O}$ crescimento do esqueleto.

2. - Fisiologia do tecido osseo. Osteoblastos e osteoclastos. Condensação e rarefação ossea. Osteoclastose e osteoclastomas. Calciofosforo. Vitamina D.

$3^{\circ}$ - O desenvolvimento do esqueleto: Pontos de ossificação. Ossificação enostal e periostal. Os pontos diafisarios e epifisarios.

4. - As glandulas de secreção interna e seu papel nesses processos. 1 - Estimulo dos osteoblastos e osteoclastos: hipofise e paratiroides.

2 - Diferenciação tissular e formação dos nucleos de ossificação: tireoide.

3 - Sinostose das cartilagens ferteis - gonadas.

5. - Estudo radiologico do punho. Suas vantagens. Tabelas. Necessidade de uma tabela regional.

$60^{\circ}$ - Crescimento deficitario. Nanismos.

a) nànismo constitucional harmonico.

b) nanismo hipofisario.

c) nanismo tireoideu.

d) nanismo gonadal.

e) diagnostico diferencial com a açondroplasia, o raquitismo, a celiaquia e a osteogenese imperfeita.

7. - Crescimento excessivo. Gigantismo.

a) gigantismo constitucional harmonico.

b) gigantismo tireoideu

c) gigantismo hipofisario $\left\{\begin{array}{l}\text { simples } \\ \text { acromegalico } \\ \text { parcial monstruoso }\end{array}\right.$

d) gigantismo infantil gonadal.

8. - Endocrinologia e tipos constitucionais. As interrelações endocrinas. $O$ equilibrio glandular e a resultante individual.

\section{CONSIDERAÇÕES GERAIS}

O desenvolvimento individual se caracteriza por um conjunto de alterações quantitativas e qualitativas que se desenrolam harmoniosa e paralelamente, trazendo ao mesmo tempo o crescimento progres- 
sivo de massa corporal e o aparecimento e maturação de funções novas. A' medida que se alongam os' membros e aumenta a capacidade craniana, desenha-se o cortejo de caracteres sexuais secundarios; atingida a maturação sexual cessa o crescimento em estatura, predominando então o deśenvolvimento e a consolidação transversais do organismo. $\mathrm{O}$ esqueleto se robustece, completa-se o aparelho muscular e o individuo adquire as proporções harmonicas e o equilibrio organico proprios da idade adulta.

Esse desenvolvimento somatico que se alicerça em fenomenos de diferenciação tissular e na proliferação subsequente dos tecidos diferenciados e que cessa quando essa proliferação entra em decrescimo, equilibrando-se com os fenomenos fisiologicos de destruição, é regido em parte por fatores desconhecidos, ligados ao genotipo, que traz consigo os atributos do tipo constitucional e da raça. Cabe porem ás glandulas de secreção interna o papel primordial no equilibrio desse admiravel mecanismo de diferenciação e crescimento harmonicos que levam o organismo adulto às proporções medias que por convenção se denominam normais.

$O$, papel diferenciador e acelerador do metabolismo, da glandula tireoide; o estimulo exercido pelos hormonios do lobo anterior da hipofise sobre o crescimento corporal e sobre as funções glandulares; o impulso dos caracteres sexuais secundarios e o amadurecimento do esqueleto sob a ação das gonadas, são ações bem conhecidas e aceitas. Ficam ainda obscuras e em aberto possiveis ações das paratireoides, da pineal, do timus, das supra-renais.

No desenvolvimento e maturação somaticas, o esqueleto oferece um campo de indagação privilegiado, pela objetividade das verificações radiologicas e pela possibilidade de se dissociarem de maneira perfeitamente clara os fenomenos de diferenciação tissular, de crescimento e de maturação. Apresenta, alem do mais, um espelho fiel das alterações metabolicas do calcio e do fosforo, ligados com frequencia a disturbios do desenvolvimento corporal. $\mathrm{O}$ aparecimento dos nucleos osseo-formadores no seio do tecido conjuntivo ou cartilagia noso, a formação das lamelas osseas com crescimento continuo do osso, a ossificação das cartilagens ferteis, refletem de maneira perfeita o jogo das atividades glandulares que dirigem a evolução da organismo.

\section{FISIOLOGIA DO TECIDO OSSEO}

Os'osteoblastos, ou celulas formadoras do tecido osseo, são elementos mesenquimais diferenciados, capazes de produzir uma substancia fundamental, fibrilar e colagena que se impregna de sais calcareos, constituindo esse conjunto as lamelas osseas. 
Agrupados ao redor dos capilares, cujo aparecimento marca o inicio do processo de ossificação, os osteoblastos se dispõem em fileiras cerradas e secretam a substancia ossea fundamental. Repetindo-se o processo com novas gerações de celulas osteogenicas, os osteoblastos das primeiras fileiras vão ficando encerradas no seio da substancia fundamental por eles secretada, conservando ainda por algum tempo sua capacidade secretora. Forma-se desse modo uma camada ossea que cresce ao mesmo tempo por aposição continua e por expansão intersticial, á medida que aumenta a quantidade de substancia intercalar.

Predomina nitidamenta, em condições normais, o crescimento por aposição.

Englobados na substancia fundamental os osteoblastos emitem prolongamentos filiformes em todos os sentidos, adquirindo a forma definitiva de osteocitos. A substancia intercalar é então sede de precipitação de sais_calcarios insoluveis (fosfatos, carbonatos e fluoreto de calcio) libertāos de suas combinações organicas soluveis pela fosfatase, de que se mostram muito ricos os focos de ossificação.

Simultaneamente com a formação da substancia ossea e a aposição continua de novas fileiras osteoblasticas, desenvolve-se na face oposta das lamelas osseas a ação erosiva continua dos osteoclastos, celulas gigantes, multinucleares que gozam da propriedade de dissolver a substancia fundamental ossea, contrabạlançando a ação formadora dos osteoblastos. Dé sua ação corrosiva nascem as lacunas osseas, "lacunas de Howship" em que se alojam essas celulas (fig. 1).

Esses fenomenos de formação e destrúição continuas existem em condições normais e de seu balanço dependem o estado e o ritmo da ossificação. $\mathrm{Na}$ infancia e na adolescencia, idades em que predominam os fenomenos de crescimento, a ação construtiva prepondera, a formação de lamelas osseas sobrepuja largamente sua destruição e o osso aumenta longitudinalmente e em espessura. Na vida adulta, caracterizada pelo equilibrio entre o metabolismo e o catabobilismo, as ações osteoblastica e osteoclastica se contrabalançam; na osteoporose senil ou nas molestias que levám a desgaste do tecido osseo, predomina a ação osteoclastica e o osso se torna poroso e fragil, quer pela ação deficiente dos osteoblastos, quer pela atividade exagerada dos osteoclastos. Si um processo inflamatorio local estimula a ação osteoclastica, aparecem as osteoporoses toxicas ou infecciosas; si existe uma deficiencia congenita das funções do mesenquima como na "Osteogenese imperfeita" a ação insuficiente dos osteoblastos se torna responsavel pela fragilidade ossea, dando ás peças do esqueleto o aspecto de laminas de vidro, pela sua transparencia radiologica.

Si a ação osteoclastica não equilibra a formação contínua de laminas, aparecem as escleroses osseas, secundarias aos processos inflamatorios cronicos ou constitue-se a afecção conhecida como "molestia marmorea" de Albers-Schoesnberg.

Alem da ação dos osteoblastos e osteoclastos na construção e destruição de substancia ossea, devem ser considaradas ainda a influen- 
cia do metabolismo do calcio e do fosforo, assim como a presença de fosfatase e vitamina $\mathrm{D}$.

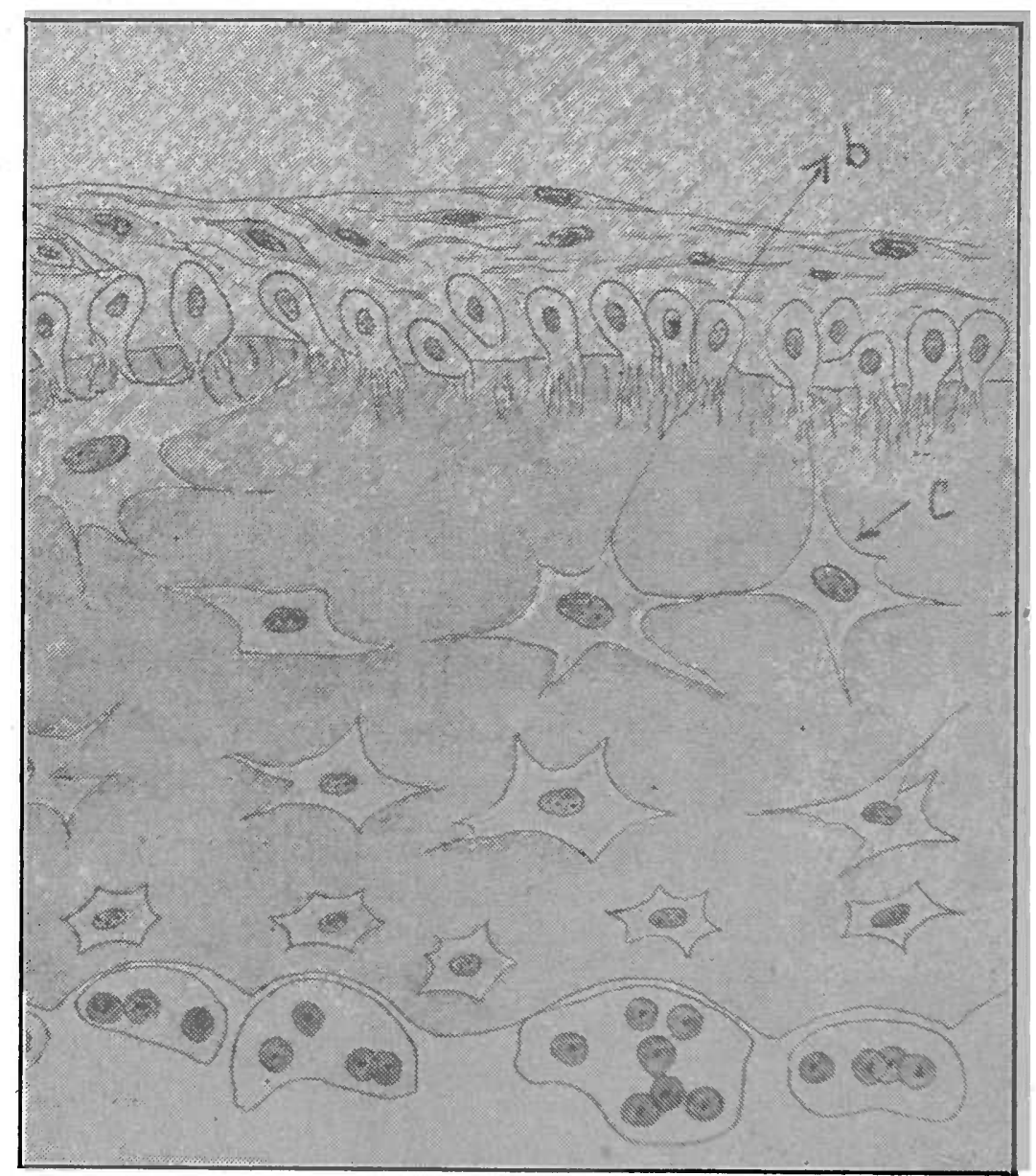

FIG, 1

Mesmo caso da fig. anterior. Sela turcica pequena, sincondrose
Reproduçāo esquematica das atividades dos osteoblastos (b) e osteoclastos em cada uma das faces da lamela ossea. Entre eles os osteocitos (c) rodeados de substancia ossea.

Nesse terreno porem estão abertas ainda muitas questões fundamentais e o que sabemos de positivo é por ora bem pouco.

A existencia de calcio em quantidade suficiente na alimentação é imprescindivel á impregnação calcarea da substancia ossea fundamental. Está estabelecido tambem que para a bôa assimilação do calcio pela mucosa intestinal necessario é que o organismo tenha um suprimento minimo de vitamina D. Alem disso, para que o calcio se fixe nos ossos, é imprescindivel uma taxa determinada de fosforo sanguineo, indispensavel á formação do fosfato tricalcido do esqueleto.

$\mathrm{E}$ ainda necessaria, para que o processo se complete, a ação da fosfatase que liberta o fosforo de suas combinações organicas ao nivel do ponto de ossificação, permitindo que ele constitua com o calcio sanguineo um sal insoluvel, que se precipita graças ao meio acido 
Esses fatos mais ou menos assentes se encadeiam por elos deșconhecidos e ficam ainda obscuras as raźões do balanço calcio-fosforo, pelo qual suas curvas seguem tragetorias ora inversas, como na molestia de Paget, em que a calcemia se eleva e a fosforemia baixa, ora paralelas, como no raquitismo, em que ambas podem baixar.

Por outro lado, a fosfatase se acha aumentada tanto na molestia de Recklinghausen, em que a demolição ossea é muito acelerada, como nos focos de ossificação ou de consolidação das fraturas, onde o anabolismo osseo predomina sobre o catabolismo.

\section{DESENVOLVIMENTO DO ESQUELETO. PONTOS DE OSSIFICAÇÃO}

No centro da diafise cartilaginosa dos ossos longos aparecé, já na vida intra-uterina, um broto vascular acompanhado de osteoblastos, que iniciam a substituição do tecido cartilaginoso pelas trabeculas osseas de nểoformação, progredindo rapidamente no sentido longitudinal, em direção ás epifises.

Nucleos acessorios de ossificação "se desenvolvem mais tardiamente, em geral na vida extra-uterina, nas extremidades epifisarias, de onde os processos de formação ossea progridem ao encontro da ossificação diafisaria. Entre esses dois focos de calcificação permanece porem uma faixa cartilaginosa, denominada cartilagem fertil que, invadida pelas suas duas faces, por trabeculas osseas de neoformação, contiuuamente prolifera, reagindo contra a propria destruiçã̃o e produzindo com essa luta o crescimento longitudinal do osso (fig. 2).

A primeira modificação que se aprecia na cartilagem fertil consiste na proliferação de suas celulas, que adquirem forma achatada e se dispõem em fileiras longitudinais, estratificadas, na disposição de "cartilagem seriada" Segue-se a este periodo a abundante deposição de sais calcareos na substancia fundamental cartilaginosa. Essa calcificação intensa é nitidamente visivel nas radiografias, como linhas densas paralelas, limitantes da cartilagem de crescimento. Botos vasculares vindos da diafise e da epifise com seu cortejo de osteoblastos e osteoclastos, penetram então nessa zona fertil, destroem a cartilagem calcificada assim como as celulas cartilaginosas já no termino de sua evolução e iniciam a construção das trabeculas nsseas. Como as celulas centrais da cartilagem fertil guardam capacidade reprodutora muito ativa, as camadas de cartilagem seriada se sucedem e o crescimento longitudinal do osso se realiza por ambas as faces da cartilagem de conjugação.

A expansão dos nucelos osseos epifisarios em direção ás cartilagens articulares, embora em menor proporção, completa o mecanismo de crescimento longitudinal do esqueleto.

Alem desses nucelos centrais, as camadas profundas do periostio, que constituem o "Cambium de Olier", são rícas em osteoblastos e formam continuamente as trabeculas osseás cerradas que constituem 
a solida camada cortical dos ossos, responsaveis por seu crescimento em" espessura.

Essa destruição de cartilagem calcica, com produção constante de tecido osseo, progride sempre durante a infancia e a adolescencia. Aos 15 anos, com a morte e ossificação completa das cartila-

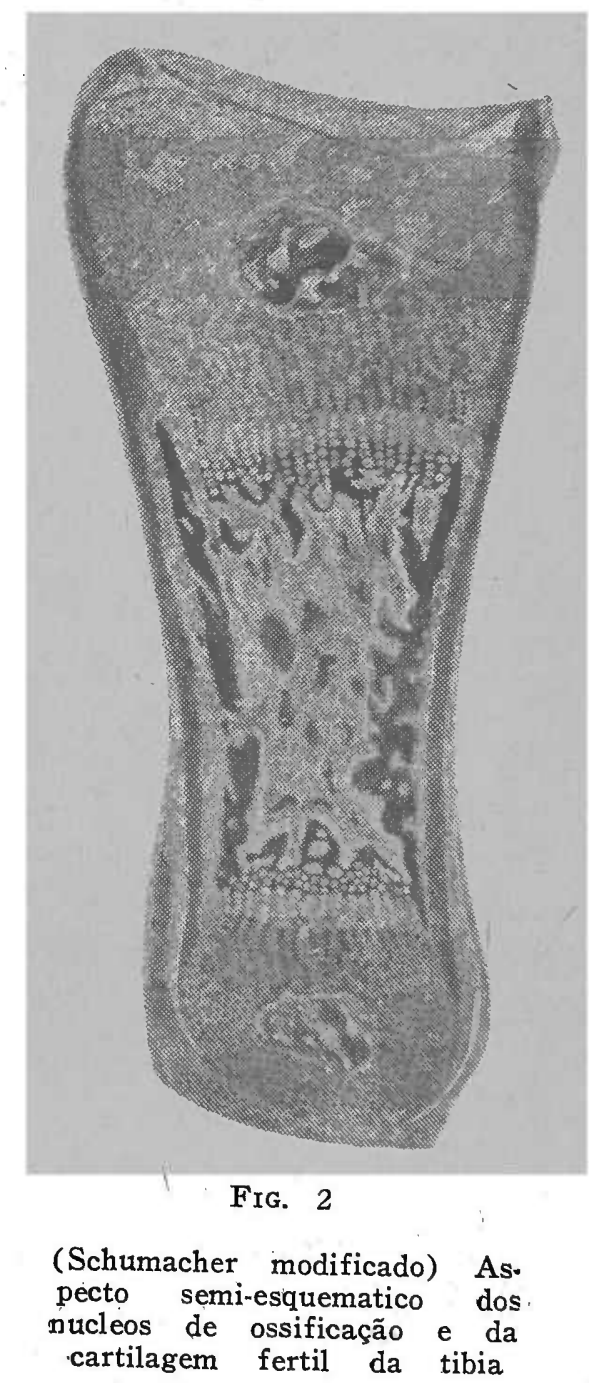

gens epifisarias das falanges, inicia-se a sinostose das cartilagens ferteis. Dos 23 aos 25 anos cerram-se as ultimas cartilagens de conjugação, do femur, da tibia, do radio e estinguem-se assim as possibilidades de crescimento longitudinal do corpo. E ainda possivel por algum tempo o crescimento periostal e os ossos ganham, por esse mecanismo, espessura e resistencia maiores.

Distinguem $\rightarrow \mathrm{se}$ assim, no crescimento dos ossos longos, 4 fenomenos distintos e fundamentais.

$1 .^{0}$ - Diferenciação dos nucleos osseos, graças á qual, no seio do esboço cartilaginoso aparece e se desenvolve o tecido osseo de neoformação.

2.0 - Crescimento progressivo por aposição e aumento de substancia intercalar, do osso neoformado, ao nivel das cartilagens de con-
jugação. 
$30^{\circ}$ - Crescimento em espessura, por atividade osteoblastica do "cambium de Olier"

4. - Morte e ossificação das cartilagens epifisarias com interrupção definitiva do crescimento longitudinal.

No desenvolvimento dos ossos curtos, apenas dois desses fenomenos estão presentes: a diferenciação e aparecimento dos nucleos e seu crescimento progressivo até serem atingidas as dimensões proprias do adulto, por substituição total do primitivo esboço cartilaginoso.

Ora, as glandulas endocrinas desempenham um papel fundamental na genese e no ritmo de desenvolvimento de todos esses processos.

$10^{\circ}$ - A difrenciação tissular em geral, e dos nucleos osseos em particular, é governada pela tireoide. A insufíciencia tireoidiana congenita ou desencadeada nos primeiros anos de vida, produz um retardo consideravel no aparecimento desses nucleos, que se mostram irregulares, fragmentados, com focos de necrose asseptica.

$2 .^{\circ}$ - O crescimento longitudinal e em espessura, estreitamente ligado á proliferação das celulas cartilaginosas, está vinculado á atividade do lobo anterior da hipofise e, por esse motivo, a hiperfunção hipofisaria eosinofila acelera o crescimento do individuo.

$3 .^{\circ}$ - A morte da cartilagem de conjugação, que acarreta sua ossificação completa e a parada do crescimento longitudinal, está na dependencia das gonadas e por isso a parada do crescimento segue de perto a maturação das funções sexuais.

$$
* * *
$$

É bem de ver que nesta disposição esquematica se trata de ação "predominante" e não "exclusiva", pois o intercambio das atividades glandulares faz com que estejam em jogo glandulas diversas,' ao mesmo tempo, na produção do mesmo fenomeno. Assim, o aparecimento dos nucelos osseos, aceito como resultado da atividade diferenciadora da tireoide, é mais precoce no sexo feminino, de 1 a 2 anos, o que mostra a influencia das gonadas no processo. A hipofise, por intermedio de seus hormonios tireo e gonadotropicos, influe indiretamente sobre os fenomenos de diferenciação e maturação ossea. $\mathrm{O}$ i poder diferenciador da tireoide, interferindo no desenvolvimento das outras glandulas endocrinas, entrelaça sua ação á desses orgãos, e assim por diante.

A predominancia de uma determinada glandula nessas ações permite, todavia, tomar o esqueleto como um teste magnifico das funções glandulares atravez dos fenomenos de diferenciação, crescimento e maturação das peças osseas.

Os nucleos de ossificação aparecem nos individuos normais em idades bem determinadas e a ossificação das cartilagens ferteis obe- 
dece tambem a uma cronologia rigorosa e assim a determinação radiologica da idade ossea oferece pontos de reparo seguros para a analise das atividades endocrinas.

$$
* * *
$$

Ao lado dos fenomenos de crescimento e maturação ossea, as glandulas endocrinas podem ser responsaveis por graves alterações do metabolismo osseo, algumas de natureza bem estabelecida, outras de mecanismo ainda obscuro.

Assim, no adenoma parratireoideu com hiperparatireoidismo existe tal exagero da atividade osteoclastica que os ossos se tornam porosos e frageis, sendo sede de frequentes fraturas por traumatismos minimos e ao mesmo tempo, formam-se acumulos tumorais de osteoclastos, verdadeiras osteoclastomas que dão lugar aos cistos osséos multiplos caracteristicos da osteodistrofia fibrosa cistica, molestia de Recklinghausen. (fig. 3-4). Na osteogenese imperfeita, em que a fragilidade ossea está na dependencia de uma insuficiencia osteoblastica, alguns autores incriminam a deficiencia congenita das paratireoides

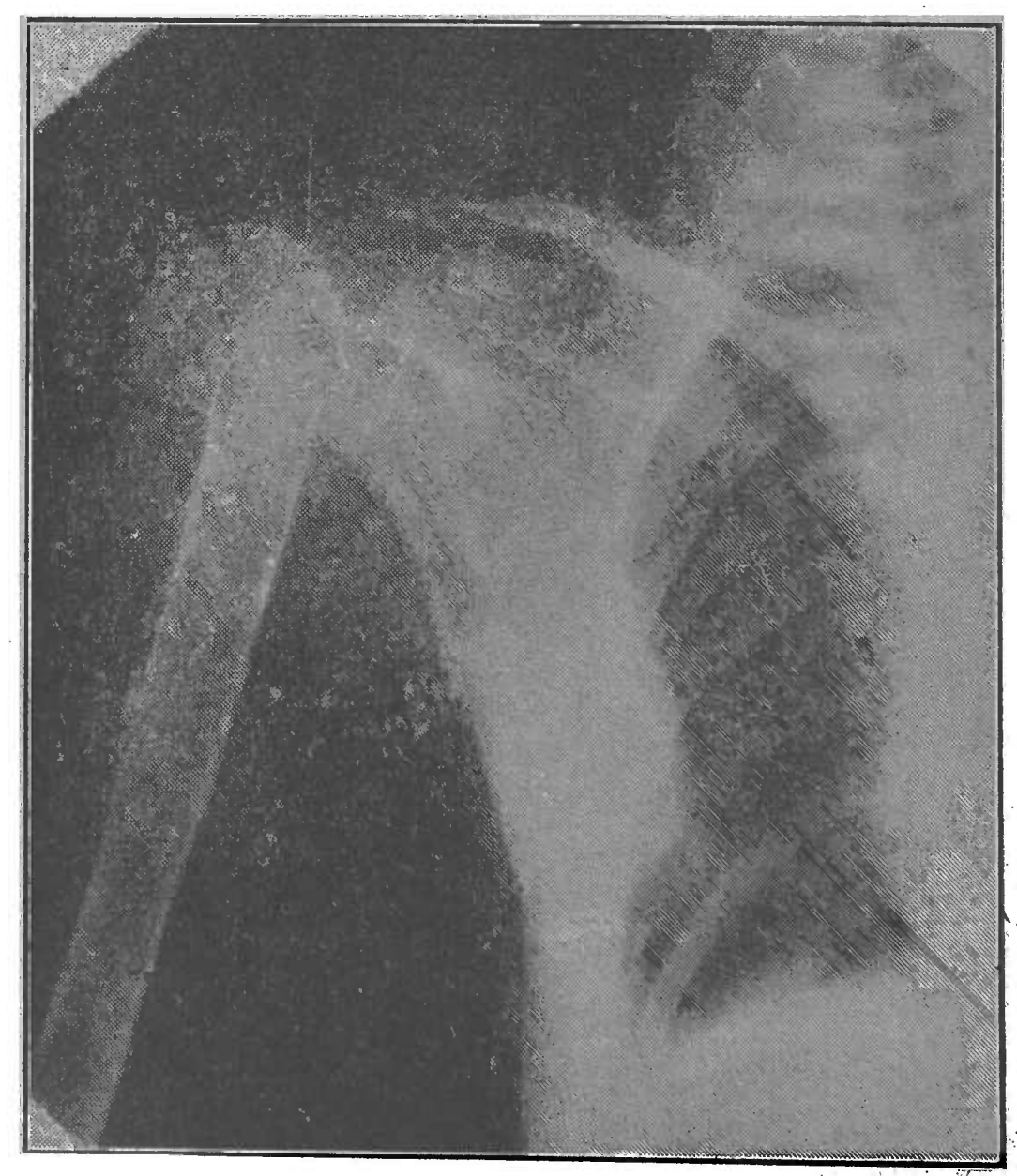

Fig. 3

J. P. - 25 anos. Caso tipico de molestia de Recklinghausen. Notar os quistos osseos do humero (com fratura patológica) e do bordo externo do homoplata e a intensa osteoporose. 
como causa da molestia; não existem todavia, por ora, fundamentos solidos que permitam afirmar essa etiologia. Osteoartroses endocrinas e osteopatias puerperais se descrevem, ainda, com maior ou menor

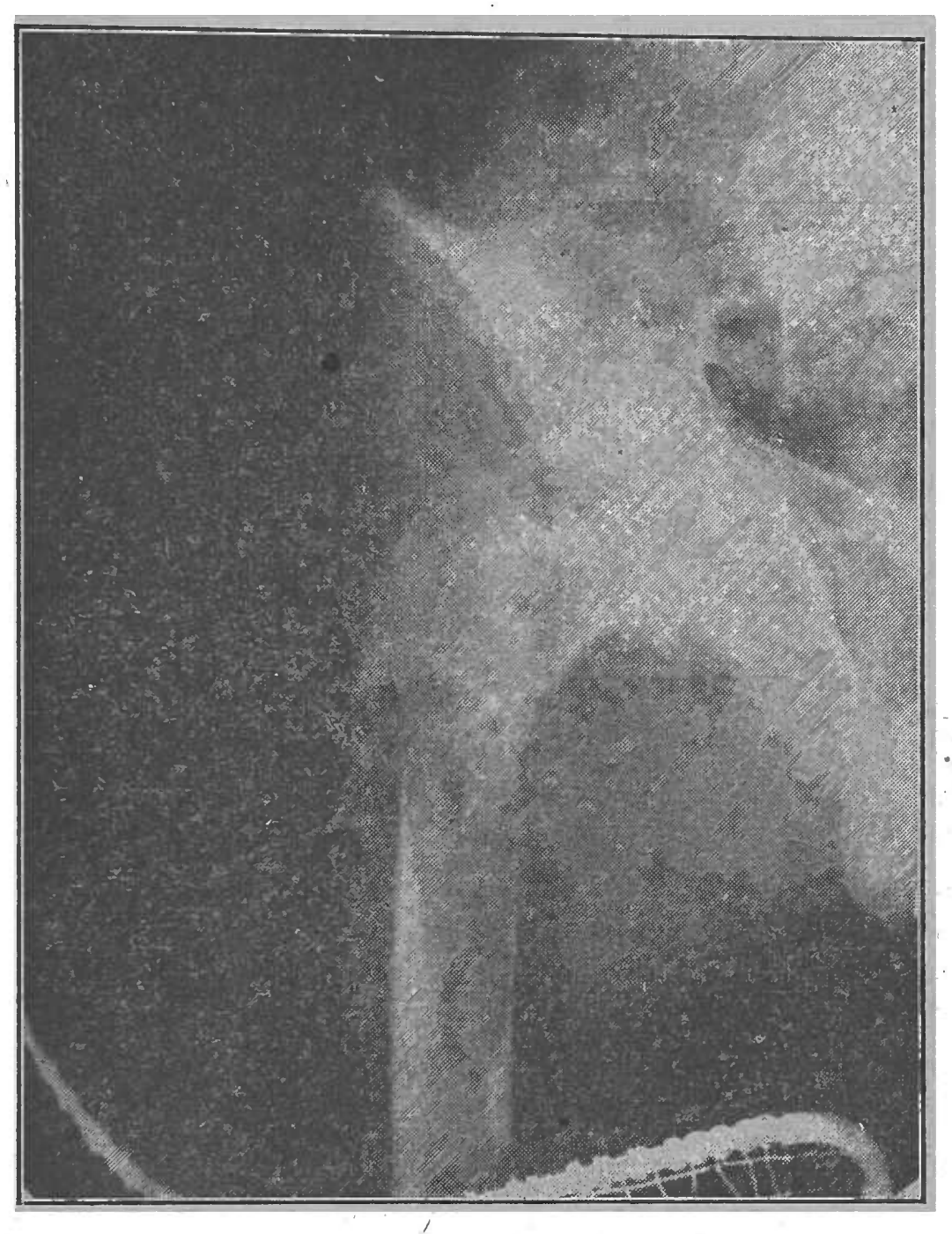

FIG. 4

Mesmo doente da fig. anterior. Quistos osseos e fratura patológica do $1 / 3$ superior do femur.

fundamento. Como, porem, não perturbam primariamente os proces sos de crescimento, escapam aos limites deste estudo.

\section{EXAME RADIOLOGICO}

O exame radiologico do esquelto, feito sistematicamente, demonstra que o aparecimento dos pontos de ossificação, assim como a soldadura das epifises ás diafises, obedece a uma ordem cronologica rigorosa; de modo que se torna possivel por seu intermedio o calculo da idade, com pequeno erro, hos individuos normais de 1 a 25 anos. 
Os nucleos diafisarios dos ossos longos; dos os sos chatos, do crànio, da face e do torax e os nucleos vertebrais, aparecem e se desenvolvem durante a vida fetal. A maior parte dos nucleos epifísarios e os nucleos do carpo e do tarso aparecem nos primeiros mezes ou anos da vida extra-uterina; excetuam-se as epifises inferior do femur e superior da tibia assim como o calcaneo, o astragalo e o cuboide, que fazem seu aparecimento ainda na vida fetal.

Aos 12 anos, todos os nucelos osseos já se formaram e continuam a se desenvolver até aos 15 , idade em que, de regra, se inicia a soldadura das epifises, a começar pelas falanageanas.

Dos 22 aos 25, ossificam-se as ultimas cartilagens ferteis (dos joelhos e dos punhos) e encerra-se definitivamente o periodo de crescimento longitudinal do esqueleto.

De modo geral, tanto a diferenciação dos nucleos osseos como a sinostose das suturas é mais precoce no sexo feminino. O aparecimento dos nucleos faz-se de 1 a 2 anos antes e a sinostose epifisaria se realiza até 4 ou 5 anos mais precocemente, nas meninas.

Existem tabelas completas que levam em conta esses fatores e pelas quais podemos seguir ano por ano a idade ossea do individụo (fig. 5). Estas tabelas constituem um otimo teste e graças a

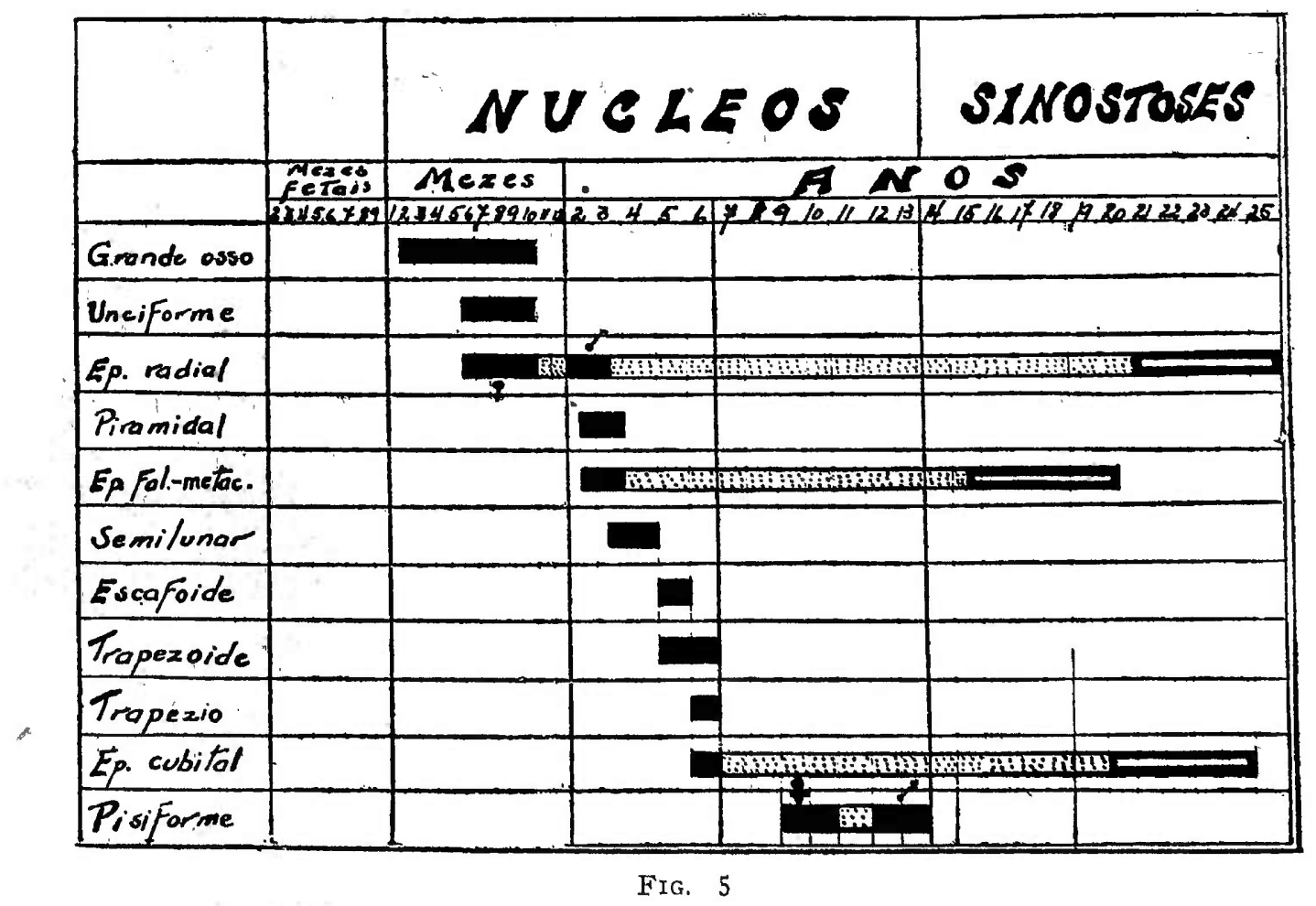

Quadro esquematico do aparecimento e maturação dos nucleos osseos do punha e das mãos, segundo SCHINZ, com pequenas modificações.

elas, e ao calculo dá idade, baseados nos principios já estabelecidos, podemos avaliar o grau de atividade das glandulas endocrinas responsaveis pelo desenvolvimento e maturação do esqueleto. No caso da fig. 13, por exemplo, tratava-se de uma moça de 16 anos com mixe- 
dema congenito. $\mathrm{O}$ aspecto da ossificação do punho corresponde a uma idade de 5 ou 6 anos.

Seria excessivamente trabalhoso, dispendioso e inutil o exame de todo o esquieleto para a avaliação da idade ossea. O exame das mãos oferece nesse particular facilidades extraordinarias, que permitem um, juizo suficiente, apenas com uma ou duas radiografias.

De fato, no carpo se encontram nucleos que se desenvolvem nos primeiros mezes da vida extra-uterina, outros que se desenvolvem durante a infancia, até aos 12 anos, idade em que o pisiforme se ossifica; nas falanges se inicia a sinostose das suturas e nos punhos termina a ossificação epifisaria do esqueleto (fig. 6).

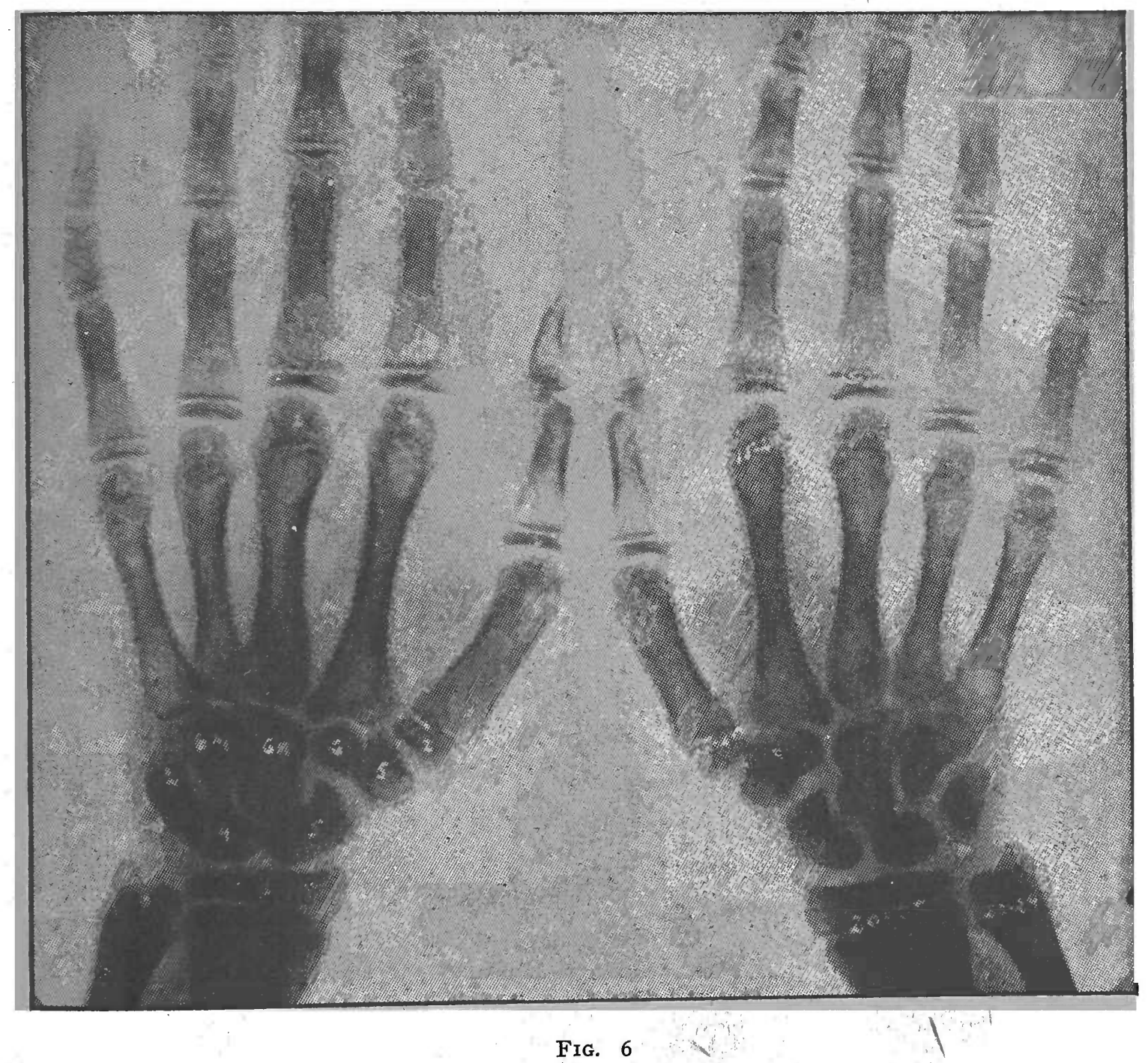

J. V. M. - Sexo masculino. Ossificação normal para a idade. São assinalados os valores médios para o tempo de aparecimento dos ossos do carpo e soldadura das cartilagens epifisarias.

Temos portanto nas mãos todos os dados suficientes, sintetizados nas tabelas abaixo, para completo estudo das condições do esqueleto. Infelizmente somos obrigados a lançar mão de tabelas extrangeiras, 
pois não existe ainda entre nós um estudo perfeito com material suficientemente abundante e bem discriminado quanto ao sexo e idade, que possa permitir o uso de um quadro regional.

\section{TABELA DE SCHINZ}

\begin{tabular}{|c|c|c|c|c|}
\hline & \multicolumn{3}{|c|}{ Aparecimento } & Sinostose (anos) \\
\hline $\begin{array}{c}\text { Epifise inf. do radio } \ldots \ldots \\
"\end{array}$ & $\begin{array}{r}1 / 2 \bar{a} \\
6\end{array}$ & & anos & $\begin{array}{l}20-25 \\
20-24\end{array}$ \\
\hline Escafoide $\ldots \ldots \ldots \ldots \ldots \ldots \ldots$ & 5 & & $"$ & \\
\hline Semilunàr $\ldots \ldots \ldots \ldots \ldots \ldots \ldots$ & 4 & & $"$ & \\
\hline$\therefore \ldots \ldots \ldots$ & $1 \mathrm{a}$ & 2 & $\dddot{~}$ & \\
\hline Pisiforme $\ldots \ldots \ldots \ldots \ldots \ldots, 9$ a 10 & e 12 a & 13 & $"$ & \\
\hline 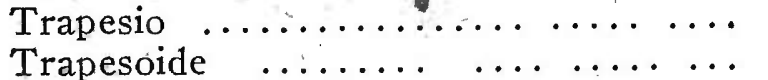 & & & $"$ & \\
\hline Grande osso $\ldots . . \ldots \ldots \ldots \ldots \ldots . . . . . . . .$. & $2 \mathrm{a}$ & & mezes & \\
\hline$\ldots \ldots \ldots \ldots \ldots$ & 5 a & & 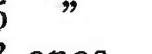 & $15 \quad 20$ \\
\hline Epifise metacarpiana $\ldots \ldots . \quad \ldots \ldots$ & $\begin{array}{ll}3 \\
2\end{array}$ & & anos & $15-20$ \\
\hline Epifise falangeana $\ldots \ldots \ldots \ldots$ & $2 \mathrm{a}$ & & & \\
\hline
\end{tabular}

Seria de toda a conveniencia a pesquisa sistematica das condições de ossificação em nosso meio e esse é um trabalho que pretendemos realizar, pois está demonstrado que variam com a raça, a alimentação é o genero de vida durante a epoca do crescimento. É um trabalho preliminár, sem o qual se torna precario qualquer julgamento das atividades endocrinas baseado no teste radiologico. Os trabalhos de Barcia no Uruguay e Sarno em S. Paulo, fazem supor, que exista uma certa aproximaçã்o entre os dados observados pelos autores alemães e os que devem vigorar para o nosso meio e nos autorizam a utilizar, em carater provisorio embora, as tabelas de Schinz.

As figuras 7 a 12 mostram os aspectos radiologicos das mãos em diversas idades, patenteando as diferenças proprias do sexo e exemplificando alguns atrazos na diferenciação ou desenvolvimento dos nucleos osseos.

\section{CRESCIMENTO DEFICITARIO - NANISMO}

Fala-se em nanismo quando existe uma pronunciada deficiencia no crescimento longitudinal do corpo, cuja estatura fica muito aquem da media para o meio e para a raça. Do que ficou exposto sumariamente no estudo da físiologia do crescimento resulta a multiplicidade de causas que podem entrar em jogo na produção do nanismo. Alem das condições raciais, de origem genotipica, o deficit de crescimento pode ser causado por uma diferenciação atrazada dos nucleos osseos, por um crescimento retardado dos nucleos já diferenciados, por uma sinostose prematura das cartilagens ferteis ou por esses fatores combinados, o que é mais frequente.

Dai a possibilidade de dispormos os nanismos em 5 grupos fundamentais : 


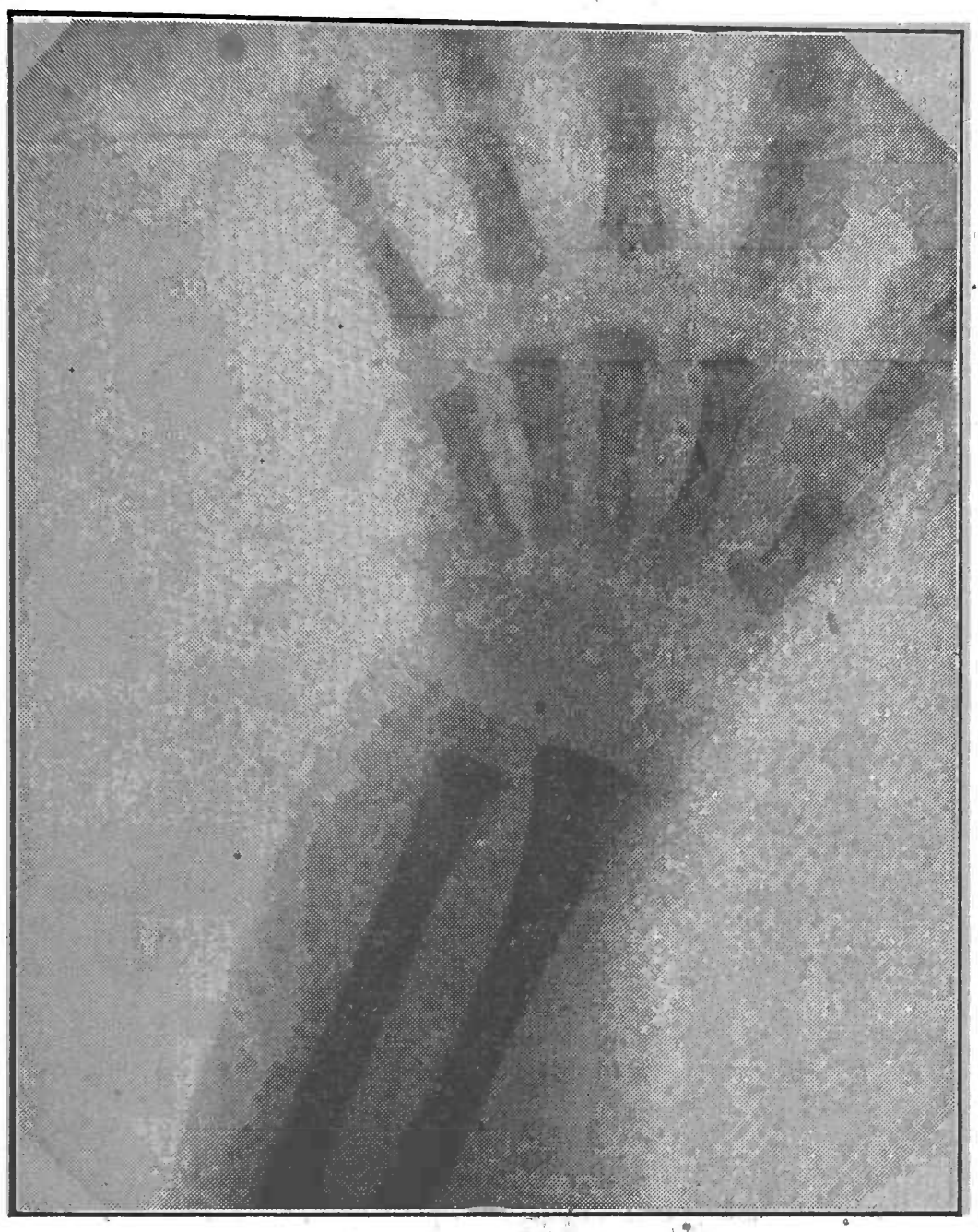

FIG. 7

Ossificação do punho no $10^{\circ}$ ano de vida. Só se notam no punho o grande osso, o osso ganchoso e a epifise radial inferior. Inicia-se a ossificação dos nucleos epifisarios das falanges.

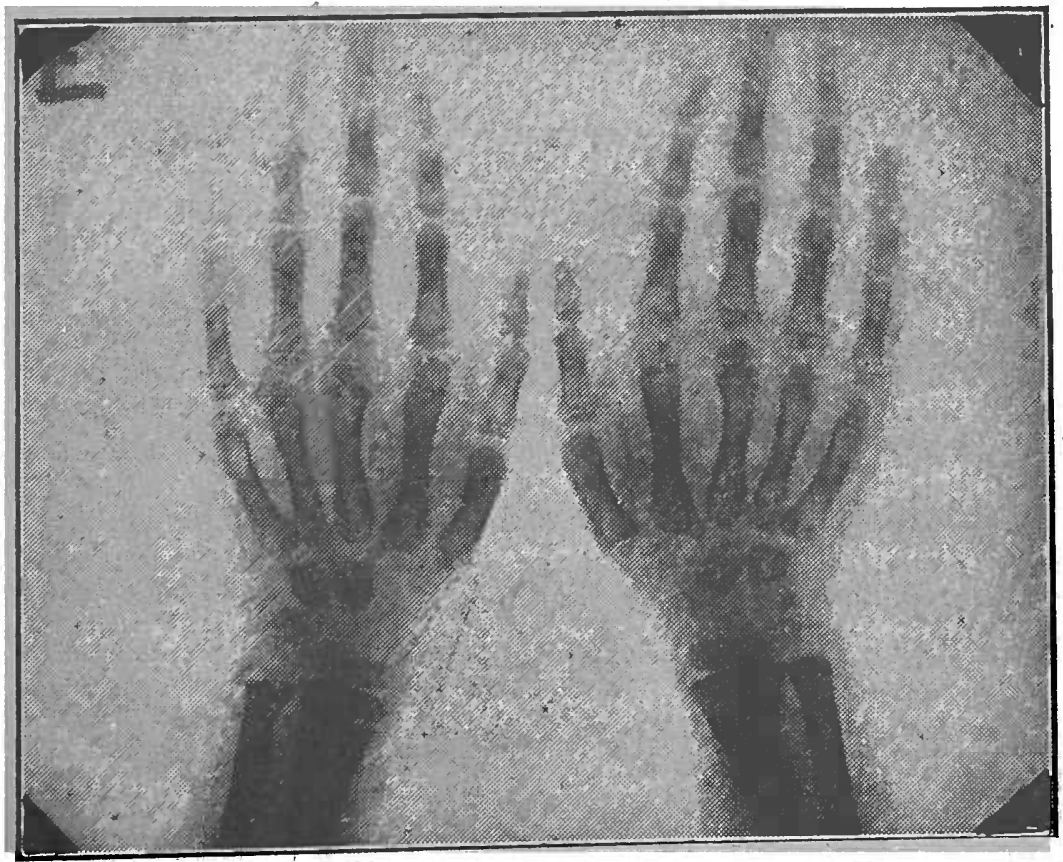

FIG. ,8

Ossificação normal do punho para uma creança de 4 anos. Fai tam ainda os nucleos osseos do trapezio trapezoide, escafoide, semilunar, pisiforme e epifise cubital. 


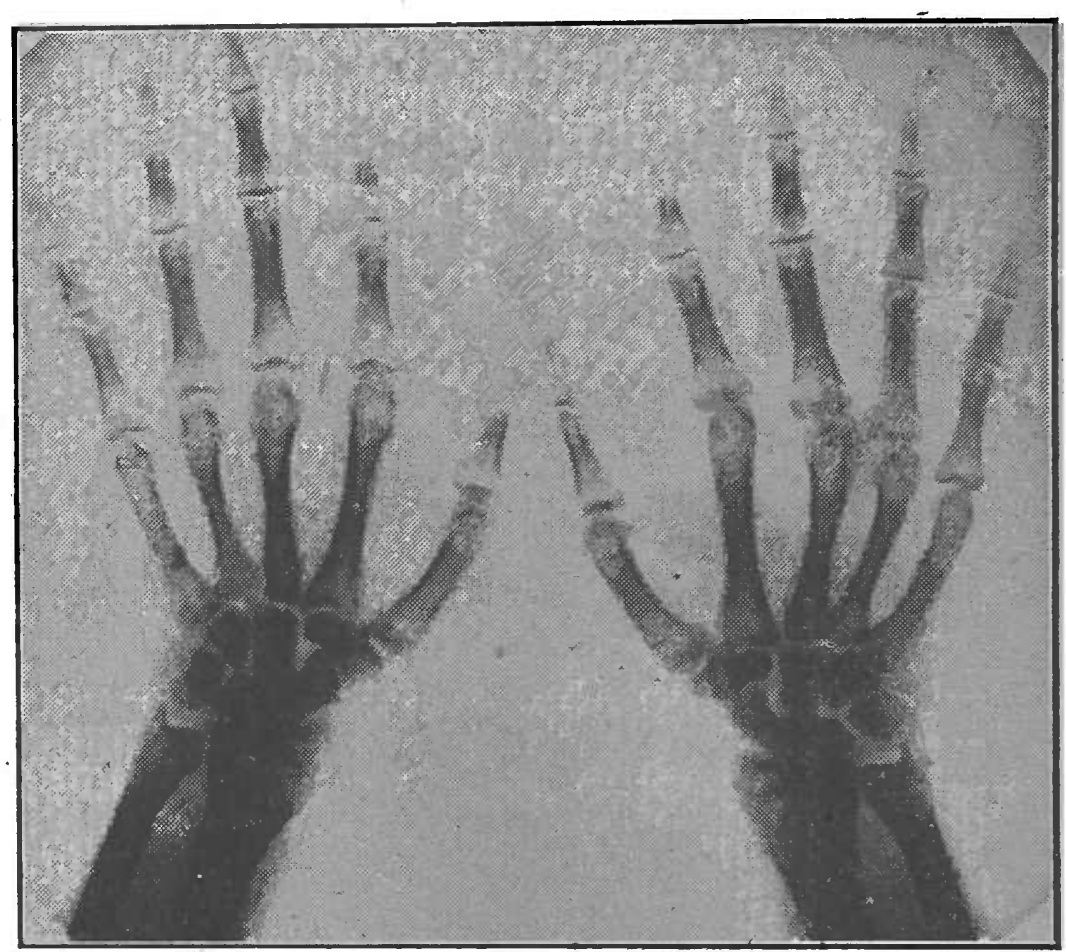

FIG. 9

V. N. - 12 anos. Sexo masculino. Desenvolvimento normal. Notar a ausencia do pisiforme.

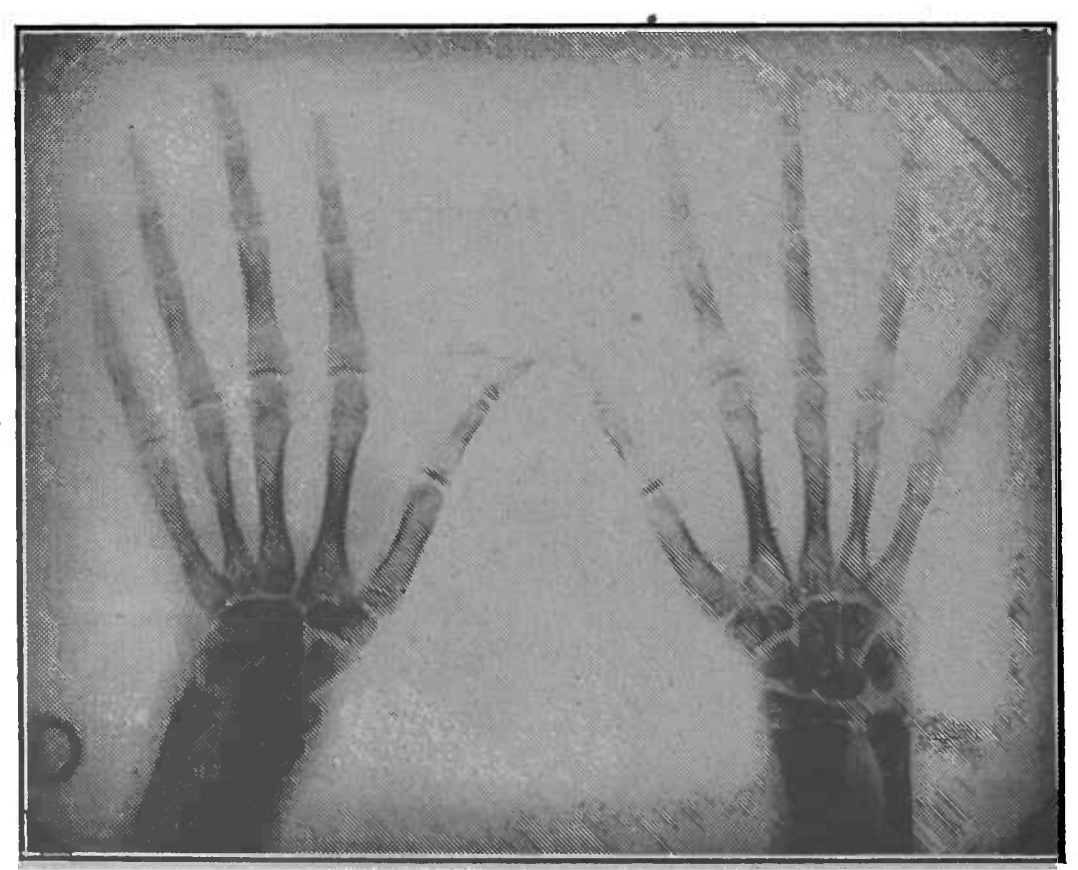

FIG. 10

A. S. S. - sexo feminino -10 anos. Desenvolvimento normai. Notar o desenvolvimento do pisiforme. 

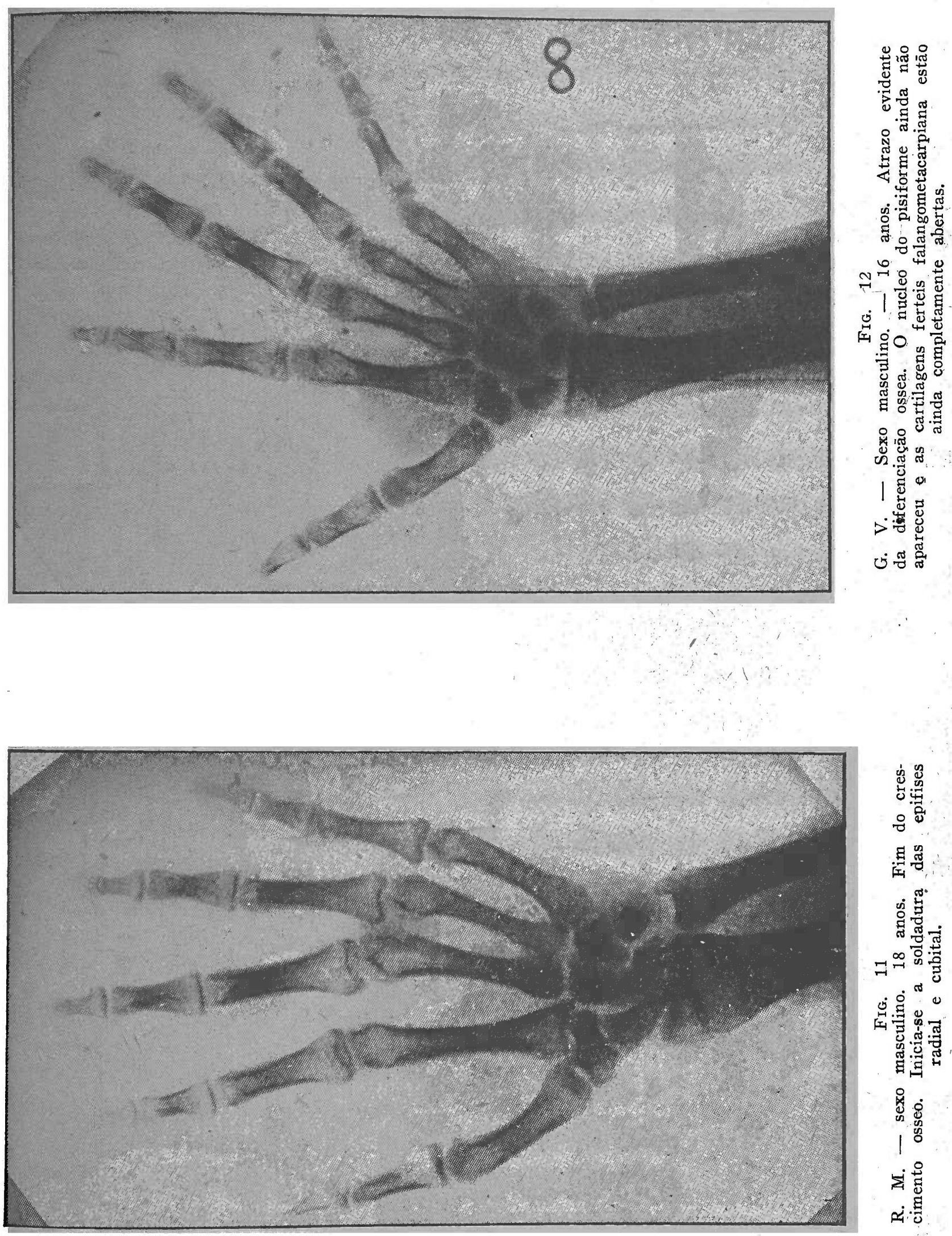

它离

表骂

เุ

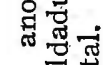

$\Rightarrow \stackrel{\infty}{\rightarrow}$



的:

离这

疋 율

: 
1. ${ }^{\circ}$ - Nanismo constitucional harmonico;

$2 .^{\circ}$ - Nanismo hipotireoideo;

3. ${ }^{\circ}$ - Nanismo hipofisario ;

$4 .^{\circ}$ - Nanismo gonadal;

$5 .^{\circ}$ - Formas mistas e incertas.

Essa distribuição deve ser interpretada como expressiva dà alteração dominante, que mais se salienta no quadro clinico, pois as interrelações glandulares fazem do tipo puro uma raridade extrema. A regra é a coexistencia de disfunções de varias glandulas endocrinas, primitivas umas, secundarias outras. Á proporção que formos estudando os varios tipos, salientaremos as associações morbidas endocrinas peculiares a cada um deles.

\section{NANISMO CONSTITUCIONAL HARMONICO}

A altura media das raças humanas varia dentro de amplos limites e entre elas se inscrevem os pigmeus cuja estatura varia de 110 e $140 \mathrm{cms}$. e que, em relação ao desenvolvimento normal da raça branca, podem ser considerados' anões. Á parte a exiguidade do talhe, os outros caracteristicos de proporções corporais e a idade de amadurecimento das funções e de sinostose das cartilagens ferteis são inteiramente normais e o desenvolvimento psiquico é perfeito. Esporadicamente aparecem na raça branca tipos semelhantes, que transmitem por herança esses caracteres de miniaturas, guardando na maturação das funções e na harmonia das formas perfeita normalidade.

São disposições essas aliadas possivelmente a alterações genotipicas ainda mal conhecidas e que reproduzem teoricamente uma deficiencia isolada do hormonio de crescimento do lobo anterior da hipofise. Os estudos radiologicos evolutivos de tais individuos ainda não são todavia suficientemente desenvolvidos para permitir um juizo definitivo sobre a genese de tais perturbações. São os anões primordiais

\section{NANISMO HIPOTIREOIDEU}

A expressão mais tipica do nanismo de origem hipotireoidiana é dada pelo cretinismo endemico, em que a degeneração estrumosa e a atrofia da tireoide se instalam desde as primeiras epocas da vida. A insuficiencia do hormonio diferenciador da tireoide se manifesta por transtornos gerais do crescimento somatico, com persistencia do tipo infantil, por graves perturbaȩões dos orgãos dos sentidos e da inteligencia. No esqueleto, é caracteristico o aparecimento tardio e irregular dos nucleos osseos. Os nucleos epifisarios aparecem com atrazo de muitos anos e se apresentam fragmentados, pontilhados e 
irregulares, reproduzindo $\mathrm{o}$ aspecto das epifisites de crescimento (molestia de Perthes, Osgoop-Schlater, etc.). O crescimento longitudinal dos ossos é deficiente e o talhe é em geral muito reduzido, frequentemente não ultrapassando um metro. Os orgãos sexuais e os caracteres sexuais secundarios, assim como as glandulas endocrinas em geral, participam dessa deficiencia de desenvolvimento corporal em consequencia da falta do hormonio diferenciador.

A soldadura das epifises se retarda consideravelmente. Como todavia o crescimento longitudinal é deficiente, apezar dessa persistencia de cartilagens ferteis a estatura se mantem abaixo da normal. Isso se dá mesmo naqueles casos em que as cartilagens epifisarias se mantêm abertas durante toda a vida.

Os atrazos no aparecimento e soldadura dos nucleos osseos não são regulares, gerando, portanto, desproporções entre os membros inferiores e superiores, a cabeça e o tronco, que fazem do "hipotireoideu" um anão desproporcionado.

Os caracteres cutaneos proprios do mixedema completam o quadro clinico dessa variedade, primitivamente hipotireoidiana, e na qual intervem secundariamente as deficiencias da hipofise e das gonadas. É possivel ainda que exista um deficit combinado e primitivo de todas essas glandulas, isto é, que se trate de uma deficiencia pluriglandular, com predominancia do deficit tireoideu.

A desproporção entre o desenvolvimento praticamente normal do esqueleto conjuntivo do cranio e seu crescimento retardado ao nivel da sincondrose esfeno-ocipital acarreta um encurtamento pronunciado da base do cranio com afundamento do nariz e prognatismo facial, compondo a fisionomia caracteristicá e comica desses anões.

Nas articulações coxo-femurais, em virtude da fragmentação nuclear da epifise superior do femur, dá-se a evolução para um tipo de osteoartrose deformante com alterações grosseiras, que se superpõem ás da molestia de Perthes. Colo femural curto e grosseiro, em coxa vara, cabeça femural achatada, acetabulo raso, com osteofitos marginais. Alterações degenerativas osteoartroticas, equivalentes, se observam em outros pontos do organismo.

Quanto mais precoce a insuficiencia tireoideia, tanto mais graves os atrazos de desenvolvimento. Casos se observam, como o das figs. 13-14-15, em que a idade ossea do paciente está 10 efmais anos aquem da idade real.

\section{NANISMO HIPOFISARIO}

A multiplicidade das funçós hipofisarias torna extremamente dificil o estudo das alteraçóes decorrentes de uma disfunçăo da hipofise. Fora a compreensão das perturbaçōes do crescimento, interessam sobretudo as funçố do lobo anterior.

$\mathrm{O}$ lobo anterior da hipofise contem celulas cromofobas, basofilas e eosinofilas, anatomica ou funcionalmente diversas. 


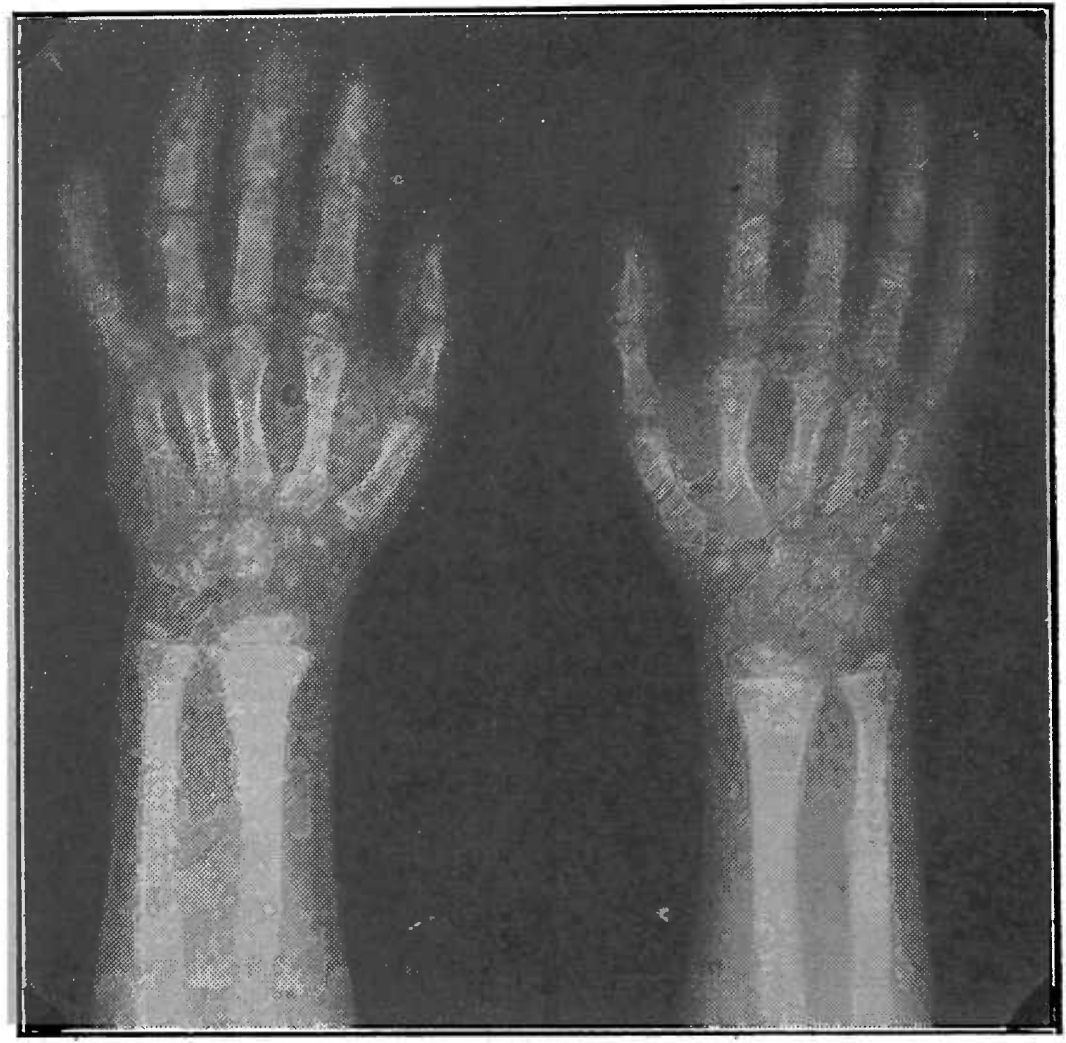

FIG. 13

P. C. - Sexo feminino. - 16 anos de idade. Estatura e de. senvolvimento somatico de uma menina de 6 ou 7 anos. Clinicamente caso tipico de mixedema com deficiencia mental (cretinismo endemico). Metabolismo a menos $30 \%$. Idade ossea do punho corresponde á de uma creança de 6 anos.

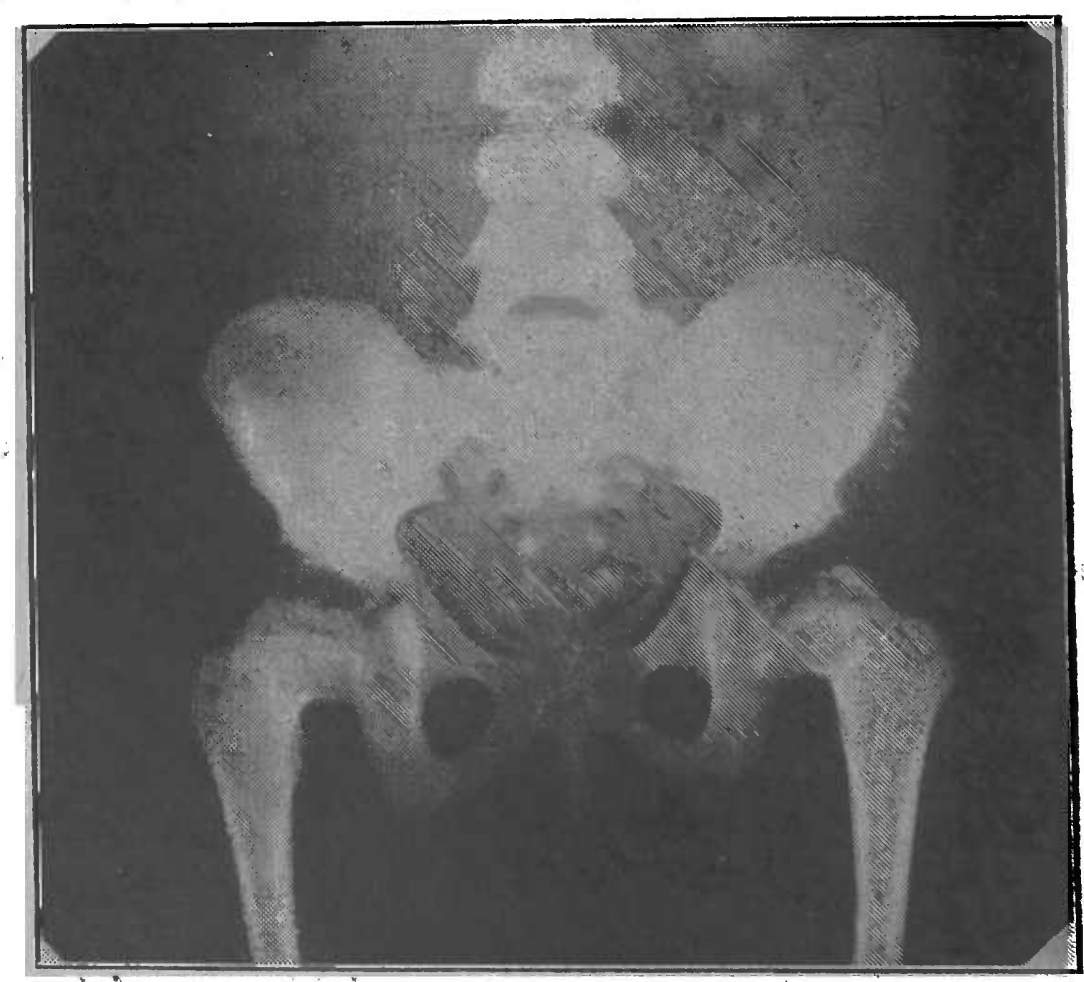

FIG. 14.

Mesma paciente da figura anterior. Aspecto tipico da "bacia cretina". Nucleos epifisarios superiores dos femures fragmentados e achatados. Colos femurais curtos, grosseiros, em coxa. vara. Cartilagens ferteis amplamente abertas. 


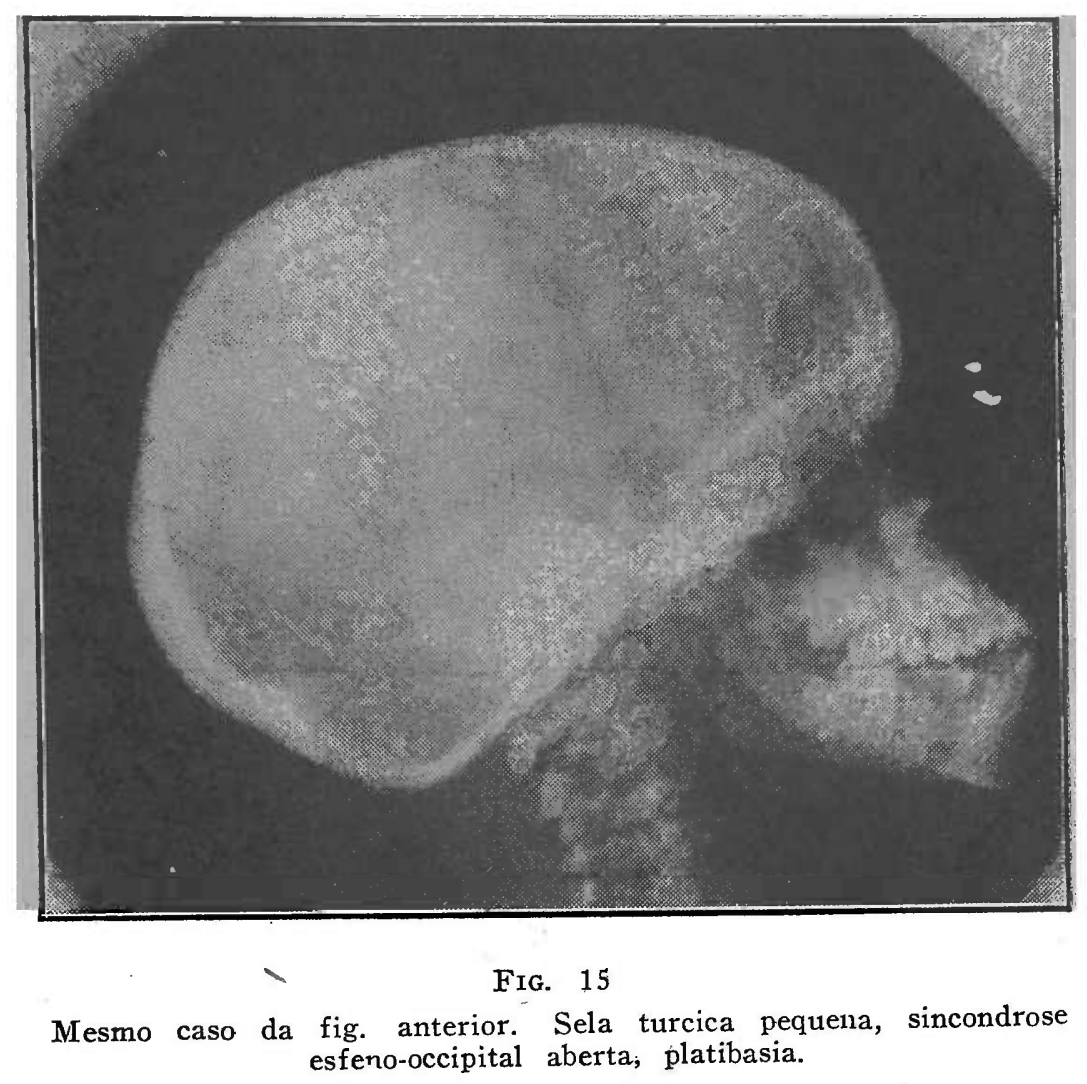

As celulas eosinofilas secretam um hormonio de cresçimento, ự hormonio estimulante das funções da tireoide, hormonio tireotropico, e um hormonio excitador da secreção lactea: a prolatina.

As celulas basofilas secretam provavelmente o hormonio gonadotropico, estimulante da atividade gonadal, o hormonio paratireotropico que atua sobre o metabolismo do calcio atravez das paratireoides e o hormonio suprarenotropico, ativador das suprarenais.

As celulas cromofobas não tem secreção hormonal por ora definida.

Outros hormonios ha, de existencia menos bem estabelecida, que não oferecem tão grande interesse para o nosso estudo: o diabetogeneo, o pancreatotropico, etc.

Por varios e entrelaçados mecanismos a hipofise pode interferir, portanto, no crescimento do 'esqueleto.

A insuficiencia hipofisaria com diminuição do hormonio de crescimento, retarda a formação ossea ao nivel das cartilagens ferteis e demora, por conseguinte, o ritmio do crescimento longitudinal. Ao cerrarem-se as cartilagens por ação das gonadas, a estatura corporal está muito abaixo da normal, estabelecendo-se assim o nanismo hipofisario. Como, ao mesmo tempo, existe, de regra, deficiencia dos hormonios tireo e gonadotropicos, verifica-se tambem no esqueleto a diferenciação tardia dos nucleos, e a sinostose retardada das carti ${ }^{2}$ lägens ferteis. Assim sendo, mesmo que as cartilagens se soldem tarde, a lentidão do crescimento não permite que a estatura atinja 
valores normais. É claro que em tais casos, um grande numero de variedades clinicas é possivel, 'de acordo com a maior ou menor repercussão da insuficiencia hipofisaria sobre as gonadas, a tireoide ou a cortico-suprarenal.-



FIG. 16

(Obs. cedida pelo Dr. MESQUITA SAMPAIO)

J. Z. - 17 anos - I. M. Homens. Caso de hipopituitarismo tipico com atrazo global do desenvolvimento somatico. Notar a fisionomia de tipo infantil e a conformação "suculenta" das mãos. $O$ aspecto corresponde ao de um menino de 11 para 12 anos.

O desenvolvimento dos orgãos sexuais e caracteres sexuais secundarios é, paralelamente, àtrazado.

Si é acentuada a ausencia de hormonio tireotropico, chama especialmente a atenção o retardo de aparecimento dos nucleos; si predomina a deficiencia do hormonio gonadotropico, o individuo apresenta desenvolvimento precario da genitalia, retardo no aparecimento dos caracteres sexuais secundarios, atrazo da soldadura das epifises, compondo o quadro de nanismo com um certo grau de infantilismo somatico (fig. 16-17). 
Nem sempre existe paralelismo exato nas secreções dos varios hormonios; frequentemente existe insuficiencia secretora predominante de um ou outro Alem disso, importa o estado previo dos orgãos receptores, no caso a tireoide e as gonadas, cuja função variavel de caso para caso reagirá de maneira diversa, segundo as proprias condições. Num individuo com hipofunção gonadal, é evidente que a deficiencia do hormonio gonadotropico se fará sentir mais intensamente.

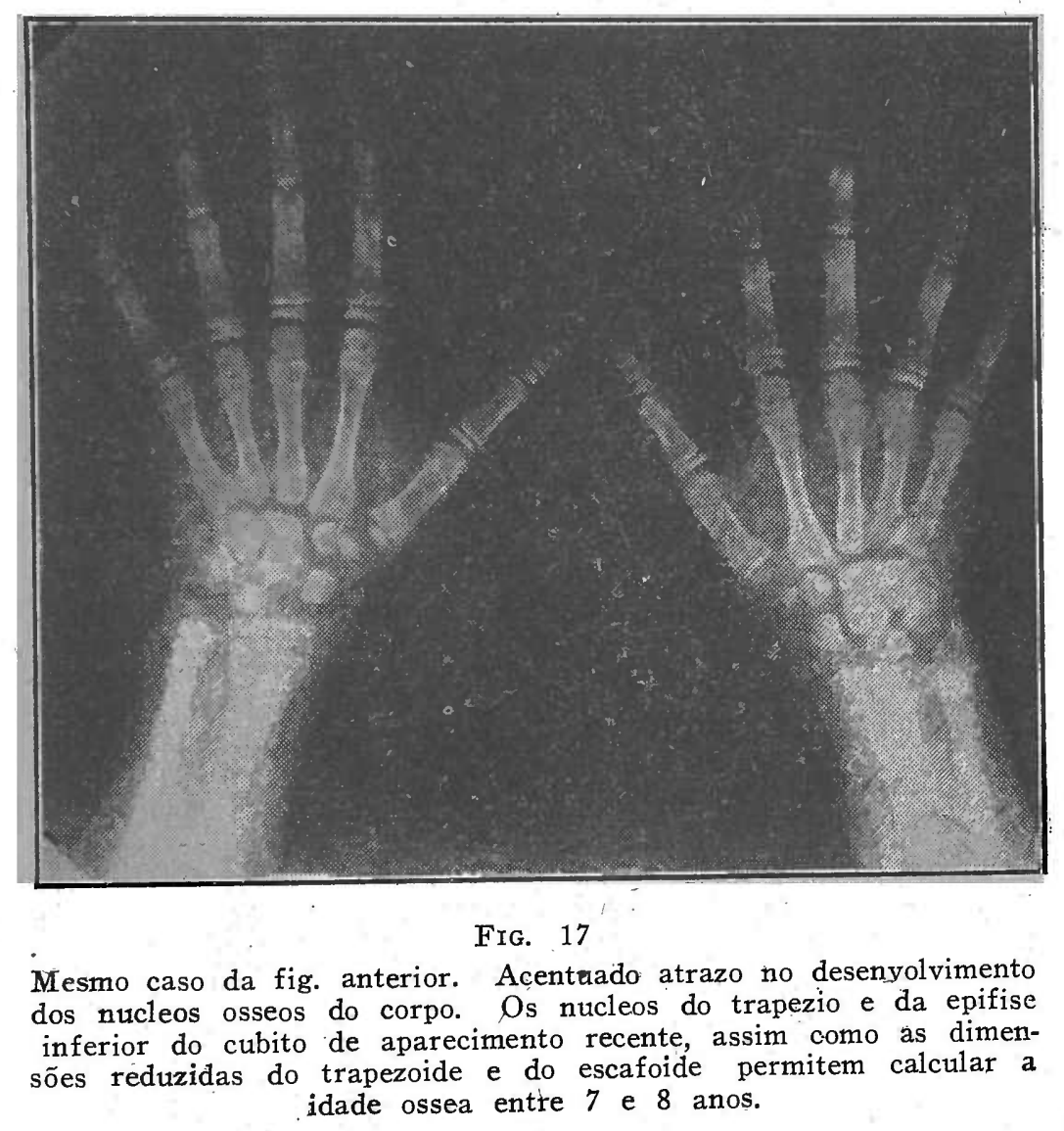

A idade em que se instala a insuficiencia hipofisaria importa tambem para as consequencias sobre o crescimento: É claro que si é muito precoce, o prejuizo é maximo; si só se instala quando a estatura já atingiu valores proximos ao normal, não pode mais influir de maneira sensivel sobre o crescimento longitudinal do esqueleto.

\section{HIPOFTSE E SELA TURCICA}

A hipofise é contida em um estojo osseo - a sela turcica facilmente focalizada pelo exame radiologico e que reflete fielmente as alterações volumetricas hipofisarias.

Ora, si bem que não exista um paralelismo rigido entre volume e função, mantêm-se entre ambos certas relações que devem ser recordadas. 
A hipofunção do lobo anterior da hipofise pode decorrer de uma falta de desenvolvimentn que atinge todas as especies de suas celulas: eosinofilas, basofilas ou cromofobas ou, predominantemente, uma delas, eosinofilas ou basofilas dotadas de funçóes hormonais conhecidas. Nesses casos, não existe aumento do orgão, a hipofise é pequena e a sela turcica é, em geral, pouco ampla, com abertura estreita, fechada por um diafragma ossificado: é a micro-sela (fig. 18). Deve-se acentuar que a reciproca não é verdadeira e que a microsela é compativel com funções perfeitamente normais da hipofise. Outras vezes, o adenoma cromofobo, que é o mais frequente dos adenomas hipofisarios, embora não traga sinais de hiperfunção, pois não se reconhecem funções endocrinas de origem cromofoba, pelo



aumento tumoral de volume que acarreta, comprime e destroe as celulas secretoras - eosinofias e basofilas - do lobo anterior, alarga e corroe a sela turcica, extendendo sua ação compressora á região infundibulo-hipofisaria. Em tais casos, ao lado das alterações osseas da sela, cujo soalho se abaixa invadindo os seios esfenoidais, aparecem os sintomas locais $\mathrm{de}^{\circ}$ comprossões nervosas, com pertur- 
bações visuais e disturbios metabolicos de origem infundibulo-hipofisaria.

Os disturbios de crescimento e maturação do esqueleto e dos orgãos genitais, já mencionados, decorrem da supressão funcional dos hormonios de crescimento, gonado e tireotropico.

É em tais casos que se instala por vezes a caquexia hipofisaria de Simonds, e a sindrome adiposo-genital de FroklLICH.

\section{NANISMO GONADAL}

O hipergonadismo, primario ou secundario, acarreta a soldadura precoce das sinfises epifisarias com parada do crescimento e estatura definitiva abaixo dos limites normais.

$\mathrm{O}$ desenvolvimento dos caracteres sexuais - morfologicos e funcionais - é acelerado e a maturação sexual é muito precoce. A maioria dos casos decorre com úma consideravel precocidade da diferenciação nuclear e do crescimento, exagerado em relação á idade, de tal modo que, embora na idade adulta o individuo vá ser anão, na infancia, relativamente, é um gigante.

São correntes os aspectos de meninos de 4 a 5 anos com estatura correspondente á idade de 10 ou 12 e maturação sexual de adulto.

Estes fatos fazem supor um disturbio primario da hipofise com aumento dos hormonios de crescimento, tireotropico e gonadotropico.

É claro que o desenvolvimento do esqueleto depende; não só do balanço desses 3 fatores como da idade em se instalarem os disturbios de secreção.

Si o hipergonadismo é primario e se instala cedo, existe nanismo pronunciado. Si a diferenciação e o crescimento são acelerados, a soldadura das epifises, embora precoce, pode apanhar o individuo com estatura normál e, em tais condições, não aparece nanismo. É o caso das figs. $19-20$ e 21 , em que o esqueleto do punho mostra a maturação correspondente á idade de 16 anos, paralela ao desenvolvimento sexual e á estatura, com inicio de sinfise dos nucleos metacarpo-falangeanos, em um menino de 10 anos. Cessa o crescimento longitudinal, podem progredir as dimensões transversais: os ossos se alargam, as diafises se espessam e as formas do esqueleto adquirem as linhas rudes das fortes inserções musculares do adulto.

Nessa sindrome de "puberdade precoce" parece desempenhar um papel muito importante a região infundibulo-hipofisaria, que agiria irritando e estimulando globalmente as funções do lobo anterior da hipofise.

Entre as causas desencadeantés estariam os tumores da pineal, os pinealomás, que agiriam assim mecanicamente, por compressão, sem que estivessem em jogo éstimulos endocrinos de uma possivel sectreção pineąl. De fato, não existe ainda hoje acordo ou certeza 
quanto á ação da pineal, pelo que se torna impossivel opiniãa definitiva sobre o mecanismo de ação dos pinealomas. Os partidarios das funções endocrinas da pineal admitem que um pinealoma suprimindo essas iunções por destruição da glandula, suprimiriam, ao

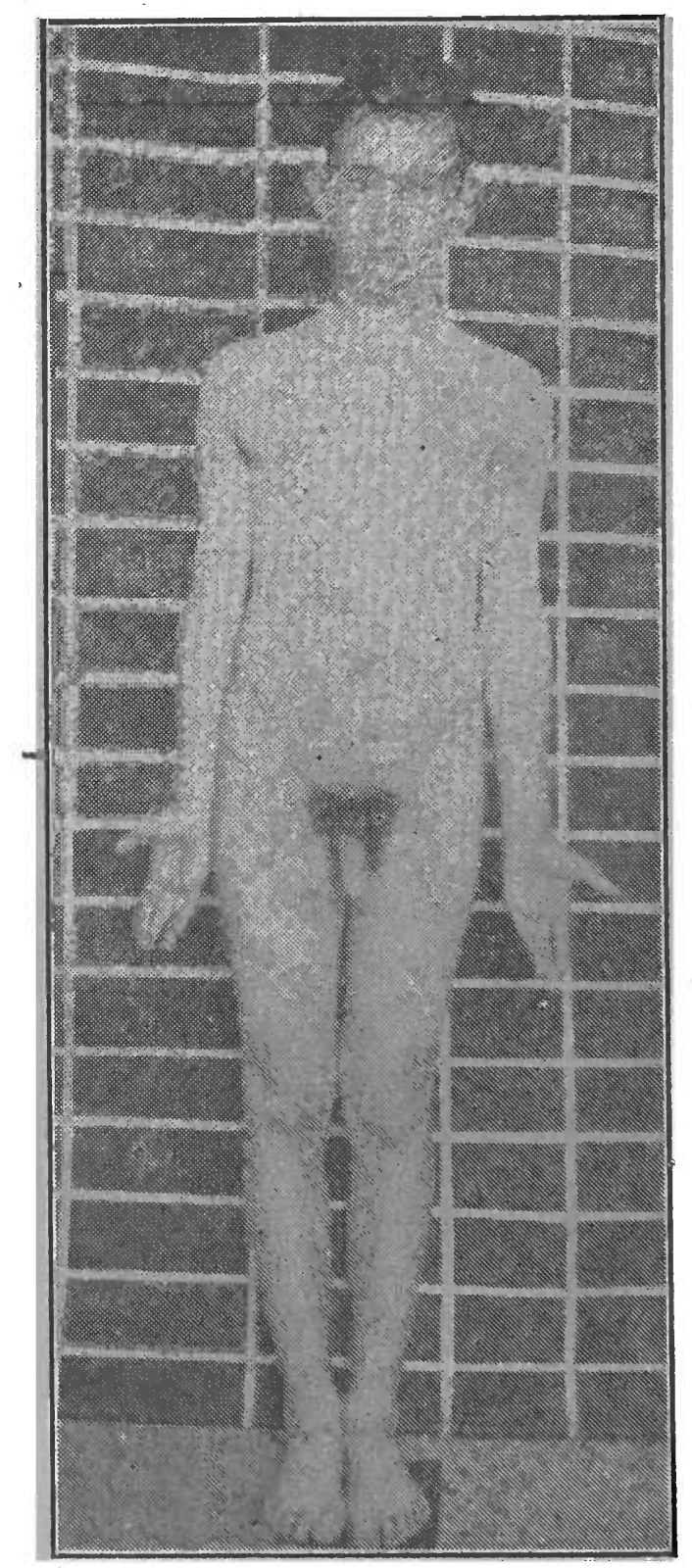

FIG. 19

F. M. -10 anos. Altura $1 \mathrm{~m} 62$. Macrogenitosomia tipica. $O$ aspecto sumatico é o de um individuo de 18 anos.

mesmo tempo, a ação inibidora que a pineal exerce sobre a hipofise. Libertada do freio pineal, a hipofise entraria assim em hiperfunção. O fato indiscutivel é que o estimulo global das funções hipofisarias explica as disfunções endocrinas que se encontram em tais tumores. 




FIG. 20

Mesmo casn da fig. arteror. $O$ asp cto radiclogico do squeleto das mic̄os correspci de aprcximadamerte á idade de 15-16 anos.

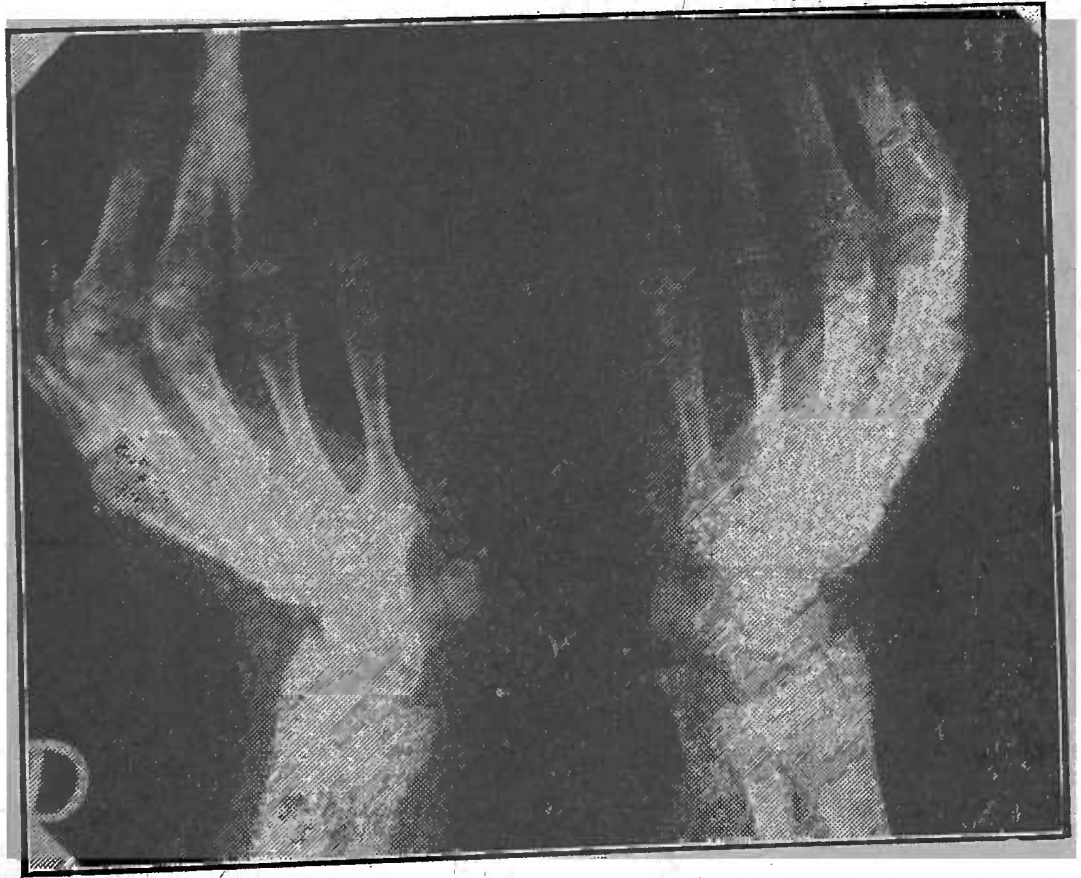

FIG. 21

Mesmo caso da fig. arterior. $O$ desenvolvimerto do pisiforme assim corho o do esqueleto da mão corrisponds ao de um moço de 15 para 16 anos. 


\section{OUTRAS FORMAS}

Existem casos esporadicos de nanismo com desenvolvimento bem proporcionado dos orgãos, com retardo da soldadura das epifises, rotulados na literatura medica $c o m$ a denominaçã́o vaga e inexpressiva de tipo "heredo-degenerativo" e cuja analise parece indicar antes a presença de uma hipofunção hipofisaria. Em outros casos, ao nanismo se associa um aspecto senil precoce com gerodermia, infantilismo sexual, queda dos dentes, dos pelos, gracilidade ossea, compondo o quadro da progeria ou nanismo senil de etiopatogenia incerta.

Pende descreve ainda um nanismo de origem paratireoidea, por deficiencia da calcificação, com alterações raquiticas dos ossos longos e hipocalciofosforemia.

De modo geral, portanto, é necèssario considerar nos nanismos, não só as interrelações glandulares, em virtude das quais as ações sobre o crescimento se somam, ou se neutralizam, mas tambem a idade em que se instalam essas perturbações, para se compreenderem os motivos pelos quais uma mesma alteração fundamental pode manifestar-se clinicamente por quadros mugitos diversos.

\section{DIAGNOSTICO DIFERENCIAL DOS NANISMOS}

Descrevem-se outras formas de nanismo, como o raquitico, o acondroplasicico, o da celiaquia e o da osteogenese imperfeita.

São todavia manifestações julgadas por ora independentes de disfunções endocrinas e escapam por isso ao nosso objetivo. Embora se tenha procurado esporadicamente atribuir á acondroplasia e á osteogenese imperfeita uma base endocrina, não existem por enquanto fundamentos solidos para tais suposições.

No raquitismo existe, por avitaminose $D$, uma deficiencia acentuada da obsorção de calcio, que se acompanha de baixa do fosforo sanguineo e consequentemente de uma deposição insuficiente de fosfato tricalcico na substancia ossea fundamental. Os fenomenos de diferenciação nuclear não sofrem perturbações e o crescimento deficitario por falta de materia prima se equilibra tesde que sejam fornecidas ao organismo as taxas minimas de vitamina $\mathrm{D}$, calcio e fosforo. Em virtude da desmineralização os ossos se encurvam ou fraturam, os membros se deformam e encurtam e o individuo se torna 
um añão desproporcionado $\mathrm{e}$ disforme. Predomina o encurtamento dos membros inferiores, constrastando com um desenvolvimento toracico relativamente conservado.

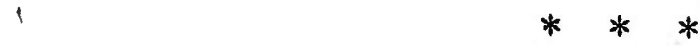

$\mathrm{Na}$ celiaquia a perturbação primitiva parece residir na absorção deficiente dos alimentos ao nivel do delgado, o que explica a origem carencial da intensa osteoporose que se observa em tais casos. $\mathrm{O}$ desenvolvimento corporal e o crescimento do esqueleto sofrem as consequencias dessa intensa hiponutrição cronica. O aspecto radiologico dos ossos é de gracilidade geral e osteoporose acentuada.

$\mathrm{Na}$ osteogenese imperfeita existe pronunciada deficiencia osteoblastica e os ossos se apresentam quasi transparentes, muito pobres em calcio, com numerosas fraturas espontaneas, mal consolidadas; cóm cavalgamentos, curvaturas e acentuada diminuição do comprimento total. A proliferação de tecido osteoide, a diferenciação dos nucleos osseos e a soldadura das epifises parece não sofrer alterações. Como se observa ao mesmo tempo adelgaçamento do tecido conjuntivo do globo ocular, a camada pigmentar da retina se torna visivel por transparencia e assim, as "escleroticas azues" constituem um sintoma da molestia. Embora alguns autores, como Bolton, tenha lembrado a possibilidade de uma hipofunção das paratireoides na genese da molestia, predomina ainda a hipotese de $\mathrm{K}_{E Y}$ de uma insuficiencia congenita do mesenquima de que fazem parte os tecidos osteoformadores e a conjuntiva ocular.

$\mathrm{Na}$ acondroplasia predomina o crescimento em espessura dos ossos longos, com diafises grosseiras, epifises rudes e fortes inserções musculares. O crescimento longitudinal dos ossos é escasso e acarreta um nanismo desproporcionado em que é notavel o contraste entre a cabeça e o tronco de desenvolvimento normais e os membros curtos e grossos que dão a esses anões uma figura comica caracteristica. A diferenciação dos nucleos osseos é regular, porem a sinostose das epifises se realiza précocemente. Não existe documentação convincente sobre umá eventual participação da hipofise. Os sinais de hiperfunção das gonadas \$ão evidentes, pois os orgãos genitais se desenvolvem precoce e intensamente. Segundo Jansen esse nanismo dependeria de um defeito congenito do proprio esboço cartilaginoso do esqueleto, porem essa hipotese não explica de modo claro a hiperfunção gonadal, responsavel pela ossificação precoce das suturas e que parece atrair a condrodistrofia para a orbita das endocrinopatias. 


\section{GIGANTISMOS}

Das noções ja expostas, deduz-se a multipliçidade de causas que se podem responsabilizar pelo crescimento excessivo dos ossos longos, gerando os excessos de talhe que constituem o gigantismo.

A precócidade da diferenciação dos nucleos, o aumento do metabolismo geral, a aceleração do crescimento longitudinal, o retardo das sinfises são processos que, isoladọs ou combinados, entram na genese do crescimento excessivo.

Podemos portanto dispor os gigantismos em grupos, á semelhança do que fizemos para os nanișmos, obedecendo ao criterio da perturbação mais evidentemente em jogo.

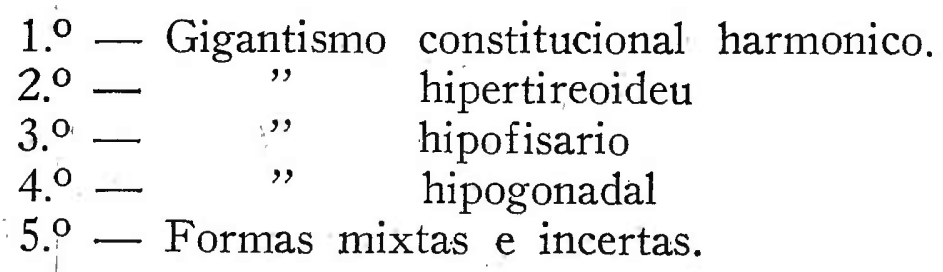

\section{GIGANTISMO CONSTITUCIONAL HARMONICO}

Ao lado do nanismo racial, existem raças de estatura media elevada, cujos individuos parecem gigantes em $\cdot$ face do tipo medio tropical. São gigantes constitucionais harmonicos, cujas funções de diferenciação e amadurecimento se desenvolvem de modo regular. As variações entre esses tipos e os opostos, pigmeus, parece ser antes quantitativa que qualitativa.

$\mathrm{Na}$ realidade não existem ainda estudos comparativos suficientemente bem documentados a respeito das diferenças raciais na aparição e soldadura dos nucleos osseos.

Talves essas diferenças raciais de estatura tenham por base diversidades nas funções glandulares.

\section{GIGANTISMO HIPERTIREOIDEU}

Havendo hipertireoidismo infantil, a diferenciação precoce dos nucleos e o aumento do metabolismo geral podem levar a um crescimento excessivo, com altura muito acima da media normal, embora sem atingir as proporções de verdadeiro gigantismo. Da breve menção dos autores deduz-se que tais casos são raros e de importancia reduzida. Mais frequentes são as formas associadas a outras disfunções endocrinas.

\section{GIGANTISMO HIPOFISARIO}

A hiperfunção hipofisaria que se estabelece antes da puberdade acarreta crescimento acelerado dos ossos longos e produz o gigan- 
tismo hipofisario, principalmente si a existencia de um excesso de tireo-estimulinas favorecer o aparecimento precoce dos nucleos osseos. Coexiste em geral com o aumento do hormonio de crescimento, excesso de gonado-estimulinas que levam a uma puberdade precoce. Em tais casos, mesmo que a soldadura das epifises se dê precocemente, a estatura pode já ter atingido valores muito acima dos normais.

' Os gigantismos mais pronunciados se encontram todavia naqueles casos em que existe, concomitantemente com uma hiperfunção eosinofila, insuficiencia das gonadas. Em tais condições a atividade da hipofise deixa de sofrer a ação frenadora das gonadas e alem disso, não se dando a soldadura das epifisẹ, o crescimento se prolonga muito alem a idade normal. Observam-se os mais diversos tipos conforme a natureza das alterações hipofisarias. Si a causa da.hiperfunção fôr um adenoma eosinofilo, predominam os efeitos sobre a diferenciação celular e o crescimento. Pode associar-se o estimulo gonadal, nos adenomas mixtos, e outra hipotese ainda deve ser admitida, de aumento das celulas eosinofilas com depreciação das celulas basofilas.

As consequencias diversas decorrentes dessas varias formas, quando estabelecidas na idade pre-puberal, deduzem-se das premissas já estabelecidas.

Quando a hiperfunção hipofisaria por adenoma eosinofilo do lobo anterior se estabelece no individuo adulto, no qual já se deu a sinfise das cartilagens ferteis, o crescimento longitudinal dos ossos não é mais possivel. Nessas condições o crescimento periostal se prolonga, com intensidade exagerada e os ossos se tornam densos, grossos, com espessamentos da cortical e inserções musculares grosseiras. Os ossos cratos e curtos, os maxilares e os ossos da aboboda craniana aumentam de espessura; as partes moles proliferam anormalmente e o indivduo, de maxilares proeminentes, labios grossos, lingua volumosa, mãos e pés enormes, apresenta as feições tipicas da acromegalia. De acordo com esse mecanismo, a acromegalia pode ser assim compreendida como o gigantismo parcial, disforme, do adulto (fig. 22-23-24).

Existem na verdade casos bem compreensiveis de individuos com gigantismo hipofisario prepuberal e que apresentam ao mesmo tempo os caracteres acromegalicos do esqueleto. São aqueles nos quais se manifestaram contemporaneamente os excessos de crescimento osseo no sentido longitudinal e transversal. 
-Descrevem-se ainda casos de gigantismo parcial monstruoso, em que o crescimento excessivo só atinge um membro ou parte de um membro, com deformação consideravel das proporçóes corporais. São porem casos raros, mal estudados e em relação aos quais se torna dificil, por esse motivo, dizer si existem funções glandulares perturbadas ou se se trata de alterações de ordem genotipica.

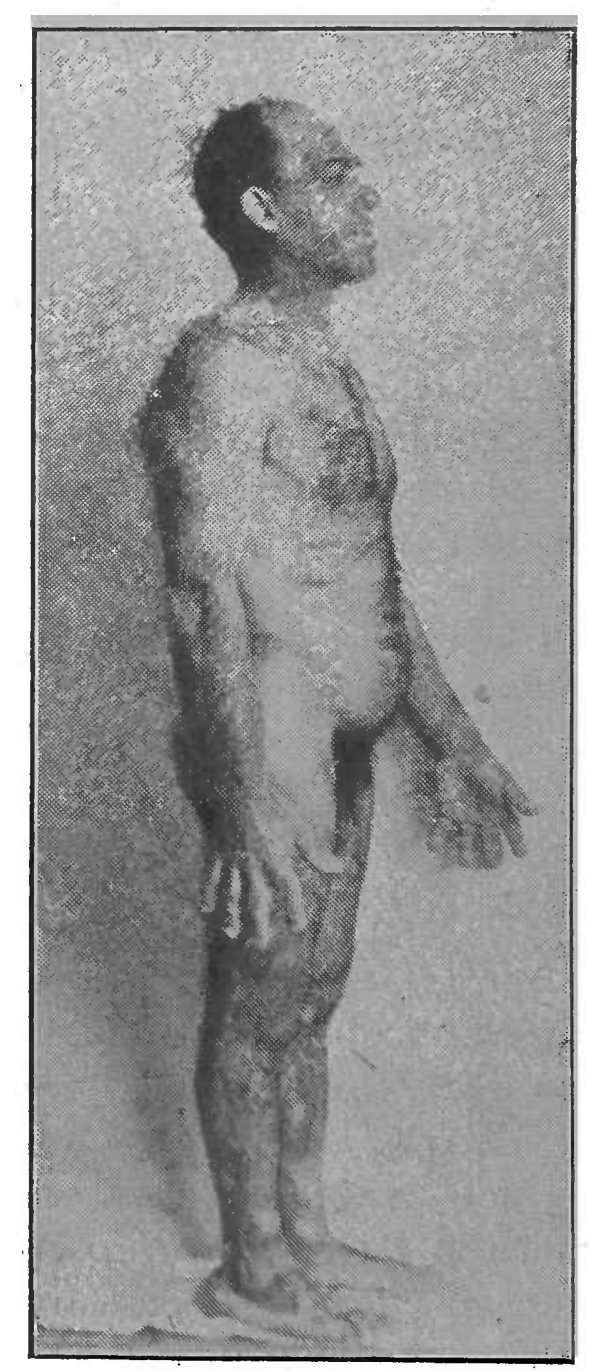

Fig. 22

Z. S. S. - 40 anos. I. M. H. Aspecto acromegalico tipico por adenoma eosinofilo do globo anterior da hipofise: Notar o. đe. senvolvimento e o aspecto grosseiro das mãos e pés. Prognatismo, engrossamento do nariz e saliencia das arcadas superciliares.

\section{SELA TURCICA E ADENOMAS DA HIPOFISE}

Já descrevemos alargamentos da sela turcica nos adenomas cromofobos da hipofise. Os adenomas basofilos de CusHing não existem como formação tumoral macroscopica. Quanto aos adenomas eosinofilos, responsaveis pelo gigantismo hipofisario e pela acrome- 


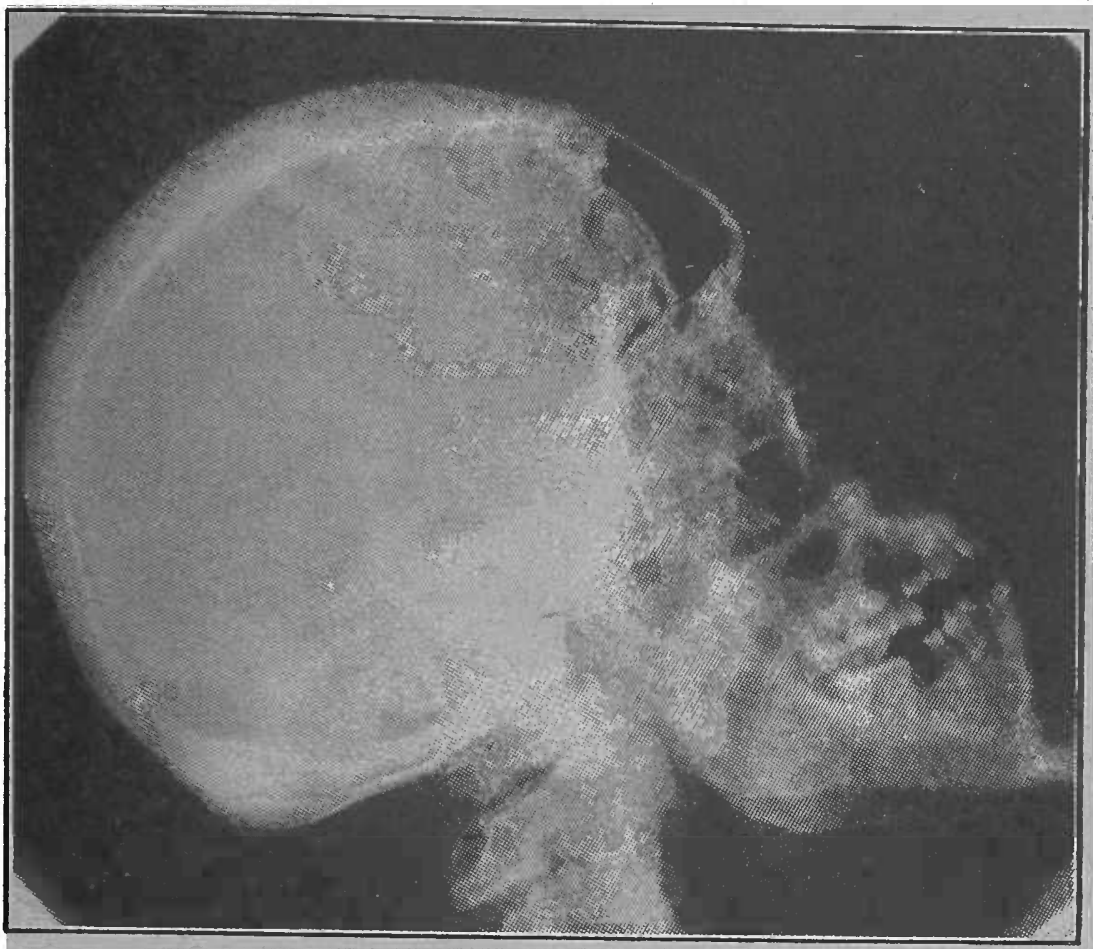

FIG. 23

Mesmo caso da fig. anterior. Cranio acromegalico tipico; grande desenvolvimento dos seios frontais; prognatismo; acentuaçāo da protuberancia occipital externa; aumento da densidade e da espessura do esqueleto craniano.

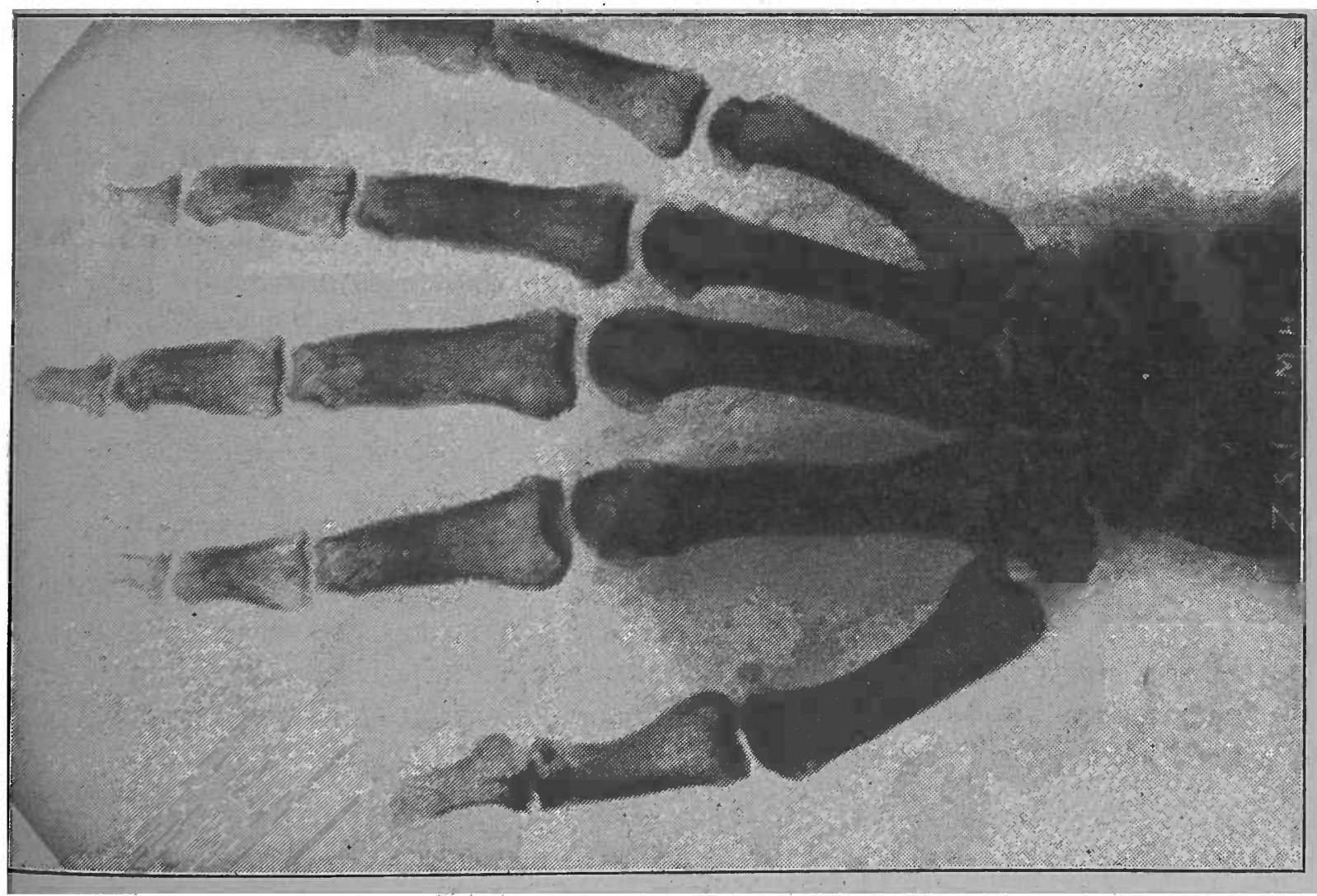

FIG. 24

Meșmo caso da fig. anterior. Notar a esclerose ossea e o aspecto grosseiro dos metaciarpianos. 


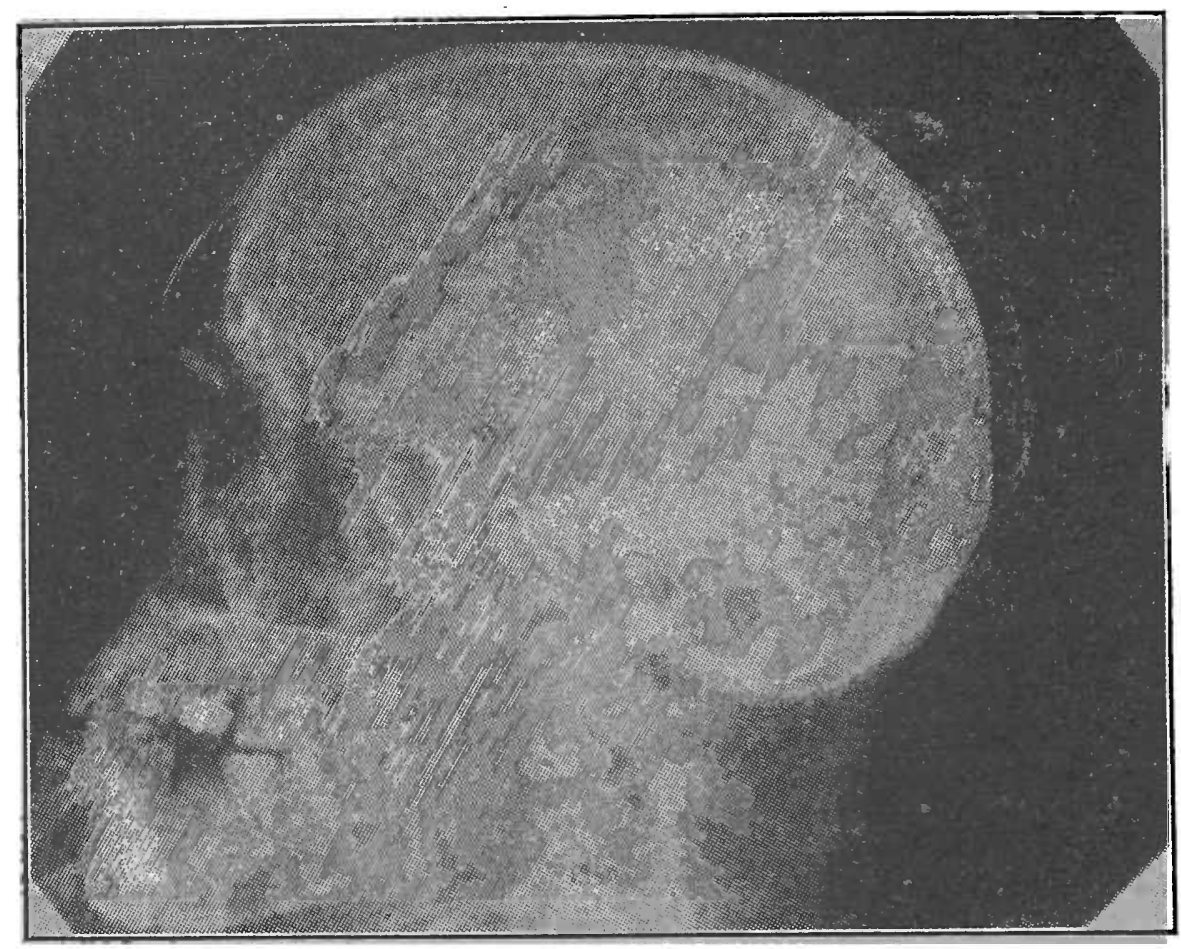

FIG. 25

Cranio acromegalico tipico. Notar o aspecto da sela, com alargamento simetrico, abaixamento do assoalho e afilamento do dorso Prognatismo; grande desenvolvimento dos seios frontais

galia, são tumores benignos, de crescimento lento, que alargam simetricamente a sela turcica em todos os seus contornos, afilando o dorso e impelindo o assoalho para baixo (fig. 25). A abertura da sela, que se mantem com as dimensões habituais durante algum tempo, acaba por abrir-se desmesuradamente quando o tumor cresce para cima rompendo o diafragma selar. Ao mesmo tempo o cranio do acromegalico apresenta alterações tipicas; os seios da face são enormes, os maxilares grosseiros e proeminentes, a protubrancia occipital externa e as arcadas superciliares são muito salientes, e algumas vezes aparece a hiperostose interna dos frontais.

São disturbios- de crescimento localizados dos ossos do cranio e da face.

Não se pode todavia esperar o encontro de todas essas alterações selares nas sindromes de hiperfunção da hipofise, pois como já acentuamos, podem existir hiperfunções consideraveis sem grandes aumentos do volume glandular.

\section{GIGANTISMO. HIPOGONADAL}

O gigantismo hipogonadal primario puro é observado nos eunucos castrados antes da puberdade ou nos individuos portadores de 
insuficiencia gonadal desde a infancia. A ausencia de função endocrina gonadal liberta a hipofise da atividade frenadora das gonadas e acelera portanto o crescimento, por aumetno do hormonio correspondente. Ao mesmo tempo, a epoca de crescimento se prolonga muito, por falta ou retardo da crise puberal. A diferencição nuclear não parece sofrer perturbações, porem o estudo nesse sentido ainda é imperfeito.

Aparecem então os individuos muito altos, de linhas longas, com desenvolvimento escasso dos orgãos genitais e dos caracteres sexuais secundarios: Predomina nitidamente o icrescimento dos membros inferiores sobre o tronco, creando uma desproporção caracteristica do tipo. Casos existem nos quais se torna dificil diante da insuficiència gonadal e do crescimento excessivo dizer se se trata de uma alteração primaria das gonadas ou de uma hiperfunção eosinofila €om prejuizo da secreção gonadotropica da hipofise. Outros casos se apresentam, de associações morbidas hipofiso-gonadais, em que ambos os efeitos de crescimento exágerado e persistencia das cartilagens se somam, produzindo os eủnucoides de estatura maxima.

Como já méncionamos, no hipergonadismo infantil pode existir crescimento excessivo para idade e, portanto, gigantismo relativo (fig. 19). A esses gigantes infantis está todavia reservada de regra uma estatura definitiva abaixo da normal por soldadura precoce das epifises. Raramente chegam á idade adulta, pois o tumor da pineal, da cortex supra-renal ou das gonadas, responsavel por essas perturbações, leva-os geralmente á morte antes dessa idade.

$$
* * *
$$

Hipofise, gonadas e tireoide se combinam portanto de varias maneiras na produção dos nanismos e gigantismos. Os casos puros são abstrações teoricas; as combinações com predominancia de uma ou outra glandula em virtude das correlações glandulares, constituem a regra.

As descrições esquematicas apresentadas representam apenas os pontos de apoio teorico sobre os quais baseamos nosso raciocinio na analise das modalidades infinitas dos casos concretos. Tem a utilidade de fornecer um andaime logico sobre o qual se constroem os diagnósticos clinicos e permitir a compreensão de minucias que sem esses fundamentos ficariam sem explicação razoavel.

\section{FUNÇÕES ENDOCRINAS E TIPOS CONSTITUCIONAIS}

A simplés descrição dos tipos somaticos resultantes das disfuncóes glandutlares acorda imediatamente a idẹ́ia da enorme importan- 
cia das glandulas endocrinas na constituição morfologica do individuo.

O hipogonadal, alto, delgado, de musculatura pobre e o hipergonadal baixo, atarracado e robusto com predominancia das linhas transversais, se inclinam indisfarçavelmente para os tipos hipo- e hiperestenico.

Ora, dentro das variações fisiologicas das funções glandulares, antes de entrar no terreno da patologia, o tipo morfologico se encontra provavelmente sujeito á constituição endocrina e nesse particular as ideias de PENDE, fazendo por assim dizer a sintese endocrino-constitucional, são de uma importancia enorme não só para a compreensão como tambem para a profilaxia e o tratamento das condições morbidas ligadas ao biotipo.

Nessa sintese, o hipertireoideu de PENDE é o simpatico-tonico, longilineo, de excitabilidade exaltada, hipotenso, intelectual, predisposto, por hipocrinia ás afecções do aparelho digestivo.

O hipersuprarenal é brevilineo vagotonico, pletorico, atletico, tipo digestivo, candidato á hiperfensão e ás molestias do aparelho circulatorio.

Imbricam-se, assim constituição endocrina e genotipo, na morfologia individual, mostrando que a herança do biotipo se entrelaça á herança das funções endocrinas da maneira indissociavel.

$$
* * *
$$

O equilibrio glandular dos diversos tipo normais faz-se com predominancia de um ou outro sistema endocrino, o que 'gera dentro da normalidade todas as variantes fisiologicas. Ora, a interação das glandulas endocrinas varia não só com a intensidade das alterações da glandula lesada, como tambem com o estado previo dos orgãos receptores e em particular das outras glandulas dé secreção interna. Daí as reações diversas de individuo para individuo, responsaveis por tipos clinicos variaveis em uma alteração fundamental sempre a mesma. Por esses motivos, nas hiperfunções hipofisarias globais, ora predomina a diferenciação precoce, ora o crescimento rapido, ora os caracteres de hipergonadisno prematuro.

NOTA: Este trabalho foi feito no serviço do Prof. Raphael de Barros, a quem devemos algumas das radiografias mais tipicas, pelo que deixamos expressos nossos agradecimentos.

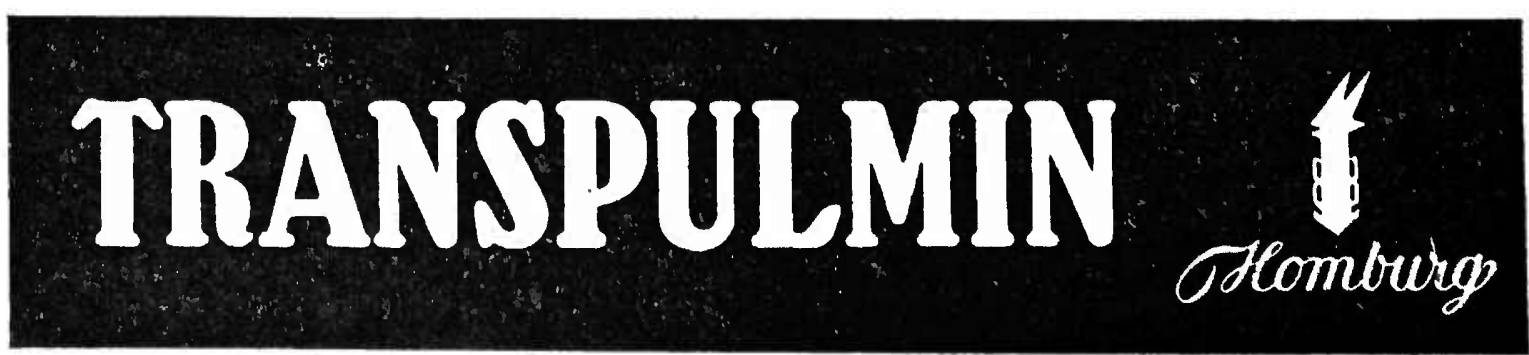






Filiais em SÃO PAULO: - Rua 15 de Novembro, 71 Rua S. Bento, 476 - Rua Florencio de Abreu, 28 Rua Barra Funda, 368 - Av. Rangel Pestana, 1843 Filiais em Santos: Rua João Pessôa, 11 - Pr. Ruy Barbosa, 34 - Filiais no Rio: Rua dos Ourives, 13 - Rua Luíz de Camões, 2, sob. - Rua'da Assembléa,70 
O Departamento Biológico dos Laboratorios Ancona Lopez Soc. Ltda., tendo como consultor científico o Dr $J$ Travassos, apresenta à distinta classe médica brasileira o seu produto:



\section{VACINA ANTI-DISENTERICA}

Enterites, Entero-Colites de natureza infecciosa bacilar

Amostras e literatura à disposição dos Senhores Médicos LABORATORIO ANCONA LOPEZ SOC. LTDA.

Laboratorios

R. Augusta, 1.426

Fone: 7-7266
Dep. Propaganda

R. Boa Vista, $15-3 .^{\circ}$ Andar

Fone: 2-0680 